OPEN ACCESS

Edited by:

Tomohiko Takei,

Tamagawa University, Japan

Reviewed by:

Yashar Zeighami,

McGill University, Canada

Yuhei Takado,

National Institute of Radiological

Sciences (NIRS), Japan

${ }^{*}$ Correspondence:

Takashi Hanakawa

hanakawa.takashi.2s@kyoto-u.ac.jp

Received: 15 September 2021

Accepted: 28 October 2021

Published: 18 November 2021

Citation:

Wakasugi $N$ and Hanakawa T (2021) It Is Time to Study Overlapping Molecular and Circuit Pathophysiologies in Alzheimer's and Lewy Body Disease Spectra. Front. Syst. Neurosci. 15:777706. doi: 10.3389/fnsys.2021.777706

\section{It Is Time to Study Overlapping Molecular and Circuit Pathophysiologies in Alzheimer's and Lewy Body Disease Spectra}

\author{
Noritaka Wakasugi' and Takashi Hanakawa ${ }^{1,2 *}$ \\ ${ }^{1}$ Integrative Brain Imaging Center, National Center of Neurology and Psychiatry, Tokyo, Japan, ${ }^{2}$ Department of Integrated \\ Neuroanatomy and Neuroimaging, Graduate School of Medicine, Kyoto University, Kyoto, Japan
}

Alzheimer's disease (AD) is the leading cause of dementia due to neurodegeneration and is characterized by extracellular senile plaques composed of amyloid $\beta_{1-42}(A \beta)$ as well as intracellular neurofibrillary tangles consisting of phosphorylated tau ( $p$-tau). Dementia with Lewy bodies constitutes a continuous spectrum with Parkinson's disease, collectively termed Lewy body disease (LBD). LBD is characterized by intracellular Lewy bodies containing $\alpha$-synuclein ( $\alpha$-syn). The core clinical features of AD and LBD spectra are distinct, but the two spectra share common cognitive and behavioral symptoms. The accumulation of pathological proteins, which acquire pathogenicity through conformational changes, has long been investigated on a protein-by-protein basis. However, recent evidence suggests that interactions among these molecules may be critical to pathogenesis. For example, A $\beta /$ tau promotes $\alpha$-syn pathology, and $\alpha$-syn modulates $p$-tau pathology. Furthermore, clinical evidence suggests that these interactions may explain the overlapping pathology between $A D$ and LBD in molecular imaging and post-mortem studies. Additionally, a recent hypothesis points to a common mechanism of prion-like progression of these pathological proteins, via neural circuits, in both $A D$ and LBD. This suggests a need for understanding connectomics and their alterations in AD and LBD from both pathological and functional perspectives. In $A D$, reduced connectivity in the default mode network is considered a hallmark of the disease. In LBD, previous studies have emphasized abnormalities in the basal ganglia and sensorimotor networks; however, these account for movement disorders only. Knowledge about network abnormalities common to AD and LBD is scarce because few previous neuroimaging studies investigated $A D$ and LBD as a comprehensive cohort. In this paper, we review research on the distribution and interactions of pathological proteins in the brain in $A D$ and $L B D$, after briefly summarizing their clinical and neuropsychological manifestations. We also describe the brain functional and connectivity changes following abnormal protein accumulation in $A D$ and LBD. Finally, we argue for the necessity of neuroimaging studies that examine 
$A D$ and LBD cases as a continuous spectrum especially from the proteinopathy and neurocircuitopathy viewpoints. The findings from such a unified AD and Parkinson's disease (PD) cohort study should provide a new comprehensive perspective and key data for guiding disease modification therapies targeting the pathological proteins in $A D$ and LBD.

Keywords: Alzheimer's disease, Parkinson's disease, MRI, functional connectivity, fluid biomarkers, PET, SPECT, longitudinal cohort design

\section{INTRODUCTION}

In parallel with global aging, the number of elderly patients with neurodegenerative diseases is rapidly increasing worldwide. Among others, Alzheimer's disease (AD) is the most common, followed by Parkinson's disease (PD) (Hou et al., 2019). AD is the most common cause of dementia (Jansen et al., 2015). People with AD have memory impairment and deficits of selfawareness as the core clinical symptoms. People with $\mathrm{AD}$ also exhibit behavioral and psychological symptoms of dementia (BPSD), including anxiety, depression and hallucinations (Jack et al., 2018). AD has key neuropathological hallmarks, including extracellular senile plaques composed mainly of amyloid $\beta_{1-42}\left(\mathrm{~A} \beta_{1-42}\right)$ and intracellular neurofibrillary tangles (NFTs) consisting of phosphorylated tau (p-tau) (Buckner et al., 2005; Jansen et al., 2015; Teipel et al., 2015; Demirtaş et al., 2017; Ishii et al., 2019). Abnormal $\mathrm{A} \beta$ and tau are considered key molecules in the etiopathogenesis of $\mathrm{AD}$. However, it remains unclear how disease-specific the abnormal $A \beta$ and tau proteins are in $\mathrm{AD}$ because these molecules are also involved in the pathophysiology of geriatric diseases other than $\mathrm{AD}$ (Galvin et al., 2011). Now it is widely recognized that $A D$ is a disease spectrum spanning from preclinical $\mathrm{AD}$, amnestic mild cognitive impairment (aMCI) and fully developed $\mathrm{AD}$ (Weiner et al., 2017).

Parkinson's disease is the second most common neurodegenerative disorder, characterized by motor symptoms, including akinesia, rigidity, and resting tremor. Non-motor symptoms include cognitive impairment, depression, anhedonia, anxiety, visual hallucination, and pain (Postuma et al., 2015). Moreover, People with PD usually have autonomic dysfunctions, including constipation, urinary disturbance, and orthostatic hypotension (Postuma et al., 2015). In PD, Lewy neurites, neurites with accumulations of protein aggregates mainly composed of $\alpha$-synuclein ( $\alpha$-syn), are present in both the central and peripheral nervous systems. These protein accumulations are considered to give rise to the various neurological symptoms (Henderson et al., 2019; Mendoza-Velásquez et al., 2019). Furthermore, it is known that systemic symptoms of $\mathrm{PD}$ not only coexist with motor symptoms, but also appear before the onset of motor symptoms (Heinzel et al., 2019). Currently, dementia in advanced PD is commonly referred to as PD dementia (PDD). As part of the PD spectrum, dementia with Lewy bodies (DLB) may start from cognitive decline leading to dementia before or almost at the same time as the development of parkinsonism. Thus, PD is also a disease spectrum spanning from prodromal PD without motor symptoms to fully developed PD/PDD and DLB (Heinzel et al., 2019), which may be comprehensively called Lewy body disease (LBD), a synonym of the PD spectrum here, from an etiopathological perspective.

Alzheimer's disease and PD spectra include many common cognitive and psychiatric symptoms and risk factors. Recently, the core pathology of $\mathrm{AD}$ and $\mathrm{LBD}$ (i.e., $\mathrm{PD} / \mathrm{DLB}$ ) has been hypothesized to share the same mechanism, called the protein propagation hypothesis (Dagher and Zeighami, 2018; Colin et al., 2020). The hypothesis posits that neurodegeneration progresses by cross-synaptic transmission of abnormal proteins with altered conformation. This could explain the observation that in both $\mathrm{PD}$ and $\mathrm{AD}$, various clinical signs gradually appear with aging, which allows the propagation of abnormal proteins. Even if this hypothesis is correct, many issues remain unresolved, such as differences in the neural circuits involved. Furthermore, the coexistence of $\mathrm{AD}$ and $\mathrm{PD}$ pathology is common in sporadic cases (Irwin et al., 2013). This coexistence may be the key to elucidating the molecular pathology of sporadic cases of $\mathrm{LBD}$ and $\mathrm{AD}$.

In previous studies, $\mathrm{AD}$ and $\mathrm{PD}$ cases have typically been enrolled in different and independent cohorts. The Alzheimer's Disease Neuroimaging Initiative (ADNIs) is a series of cohort studies of AD (Petersen et al., 2010; Weiner et al., 2017; Veitch et al., 2019), as The Parkinson Progression Markers Initiative is for PD (Marek et al., 2011). However, considering the shared pathological mechanisms, many important questions may only be resolved by studies that include both $\mathrm{AD}$ and PD spectra in the same cohort. For example, mild cognitive impairment (MCI) may herald dementia (Flicker et al., 1991). MCI initially drew attention in the field of $\mathrm{AD}$ research. However, the background pathology of $\mathrm{MCI}$ is not limited to $\mathrm{AD}$, but includes various pathological conditions such as PD (Dichgans and Leys, 2017; Baiano et al., 2020). A comprehensive cohort including different types of MCIs will likely cast new light on the prodromal stage of dementia.

In this article, we review basic research on the distribution and interactions of pathological proteins in the brains of $\mathrm{AD}$ and LBD, after briefly summarizing their clinical and neuropsychological manifestations. We also describe functional and connectivity changes in the brain in $\mathrm{AD}$ and $\mathrm{LBD}$. Finally, we will argue for the necessity for a neuroimaging cohort treating the $\mathrm{AD}$ spectrum and the $\mathrm{PD}$ spectrum as a continuum. The findings, which will be obtained from the proposed cohort study, should provide a new comprehensive perspective for these two most important neurodegenerative disorders. 


\section{ALZHEIMER'S DISEASE}

Alzheimer's disease is the most common dementia in the population over 65 years of age. The core clinical symptom of $\mathrm{AD}$ is impaired recent memory, which supposedly results from dysfunctions of the medial temporal lobe (MTL) and the hippocampus. Most patients with $\mathrm{AD}$ first present with impaired episodic memory, followed by more extensive cognitive dysfunctions, including amnesia, apraxia, and visuospatial deficits (Eramudugolla et al., 2017). These cognitive symptoms are ascribed to the dysfunctions of the temporal lobe, parietal lobe, and occipital lobe. Semantic memory problems caused by lateral temporal lobe dysfunction and insight and spontaneity deficits resulting from frontal lobe dysfunction may also be observed (Hodges and Patterson, 1997; Boublay et al., 2020).

\section{Diagnostic Criteria}

Alzheimer's disease is diagnosed primarily by clinical history. Multiple markers, including cerebrospinal fluid (CSF), neuroimaging, and genetic tests, are used as supportive findings (Jack et al., 2018). For the clinical diagnosis of AD, the following two criteria are used: (i) finding of major neurocognitive disorder (NCD), as defined by the fifth edition of the Diagnostic and Statistical Manual of Mental Disorders (DSM-5) (Eramudugolla et al., 2017), and (ii) the diagnostic guidelines of the National Institute on Aging and Alzheimer's Association (NIA-AA) (Jack et al., 2018). The common item in the two criteria is slowly progressive dementia.

DSM-5 criteria make use of genetic risks, including family history and identification of the causative genes. Cognitive dysfunctions need to be shown in two or more cognitive domains centered on the memory/learning disorders. NIA-AA criteria also consider the genetic risks and clinical symptoms, similar to DSM-5. NIA-AA also takes into consideration evidence for the existence of $\mathrm{AD}$ pathology indicated by fluid biomarkers such as CSF and imaging biomarkers such as positron emission tomography (PET).

For research purposes, the International Working Group-2 (IWG-2) criteria for AD may be used (Dubois et al., 2014). The criteria broadly classify $\mathrm{AD}$ into typical $\mathrm{AD}$, in which patients initially develop episodic memory impairment, and atypical AD, in which patients develop unique symptoms such as logopenic aphasia and frontal lobe signs. In addition, the evaluation of $A \beta$ and tau, using CSF or PET, is also essential.

Mild cognitive impairment is a condition where slight cognitive impairment is recognized objectively compared with a condition before illness, but the patients' activities of daily living are independent. MCI centered on memory deficits is clinically diagnosed as amnestic MCI (aMCI) presumably caused by AD pathology (Petersen et al., 1999, 2001). In addition, if there are findings from fluid/imaging markers indicating abnormalities in $\mathrm{A} \beta /$ tau, this condition is defined as AD-MCI (Albert et al., 2011).

\section{Neuropsychological Testing}

Neuropsychological tests for $\mathrm{AD}$ are used for screening, differential diagnosis, and severity assessment. In clinical practice, screening for dementia or MCI is performed by tests for general cognitive functions. Mini Mental State Examination
(MMSE), a simple test for assessing multiple cognitive domains, is used with a cutoff value of 23/24 for dementia (Trivedi, 2017). To diagnose MCI, Montreal Cognitive Assessment (MoCA) may be used with a cutoff value of 25/26 (Davis et al., 2015). These tests are helpful not only for screening through the assessment of total scores, but also for evaluating cognitive subcategories, including memory, attention, and visuospatial cognition.

As the disease progresses, patients with $\mathrm{AD}$ who initially had only memory impairment begin to show impairment involving multiple cognitive domains, including visuospatial cognition and language. Therefore, the Wechsler Adult Intelligence Scale (WAIS) and the Wechsler Memory Scale (WMS-R) are performed for a more detailed and comprehensive evaluation. However, because these advanced tests take more than $1 \mathrm{~h}$, they are not suitable for screening.

Differential diagnosis to estimate the background pathology of dementia cannot solely rely on the neuropsychological examination, and is accordingly usually performed in combination with the assessment of clinical course and diagnostic imaging. In clinical practice, it is important to distinguish AD from other dementias such as DLB. Typical early symptoms are predominantly memory deficits in AD; executive function and visuospatial cognition are impaired only after memory deficits become apparent (Jack et al., 2018). Therefore, for differential diagnosis of $\mathrm{AD}$, patients should undergo tests of memory, attention, executive functions, and visuospatial cognition to distinguish from DLB, in which executive function and visuospatial cognition are impaired at the early stage. However, because half of the cases of DLB are complicated by $\mathrm{AD}$ pathology, the possibility that DLB patients have AD-like memory impairment from the onset needs to be taken into account (Yoshizawa et al., 2013).

The severity assessment is essential for selecting rehabilitation and welfare services, and for longitudinal cognitive assessment in clinical research. Clinical Dementia Rating (CDR) (Morris, 1993) is a scale that evaluates general cognitive functions and community affairs, home/hobbies, and personal care. CDR yields a global scale (CDR-GS) and a sum of boxes (CDR$\mathrm{SB}$ ). CDR-GS is a general severity calculated by weighting the results of each subscale and is commonly used for disease staging. On the CDR, CDR-GS 0.5 corresponds to MCI, and 1.0 or larger corresponds to dementia (Chang et al., 2011). CDR-SB provides more information in terms of quantitative evaluation than CDR-GS, especially in MCI and early AD (O'Bryant et al., 2010). A feature of CDR is that it also refers to interviews with family members. Thus, CDR provides accurate information for understanding disease severity and significantly impaired function when evaluated by a proficient examiner that is well informed by the caregiver. Alzheimer's Disease Assessment Scale-Cognitive Subscale (ADAS-cog) is an assessment of 11 cognitive subcategories related to AD symptoms (Kueper et al., 2018). It is time-consuming, yet suitable for observing changes in cognitive function over time and is often used in clinical trials.

\section{Genetics}

Most $\mathrm{AD}$ cases are sporadic, and the most prominent risk factor is aging (Angelova and Brown, 2019). AD also has familial cases, 
and many genetic risk factors are known. In autosomal dominant $\mathrm{AD}$, mutations in proteins related to $\mathrm{A} \beta$ production, such as presenilin 1/2 (PSEN1/PSEN2) and amyloid precursor protein $(A P P)$ have been reported (Robinson et al., 2017). The mutation of PSEN1 accounts for the most common form of familial AD. PSEN1 is a component of the $\gamma$-secretase complex, which plays an essential role in the production of $\mathrm{A} \beta$. APP mutations were first reported as an etiological factor in intracranial hemorrhage with amyloid pathology (amyloid angiopathy) and subsequently identified in familial AD cases. Patients with autosomal dominant $\mathrm{AD}$ (AD-AD) with PSEN1/PSEN2 and APP mutations may exhibit predominantly motor symptoms of akinetic-right type caused by A $\beta$ deposition in the basal ganglia (Vöglein et al., 2019). Therefore, it may be difficult to distinguish some AD-AD cases from patients with PDD and DLB.

The $\varepsilon 4$ allele of the APOE gene is the most important risk factor for sporadic AD (Jansen et al., 2015), being present in more than half of all AD cases, compared with a frequency of $\sim 14 \%$ in the general population (Pontifex et al., 2018). The ApoE protein functions as a ligand for the low-density lipoprotein (LDL) receptor family on the cell, and its abnormality causes atherosclerosis. In the brain, ApoE is mainly produced by astrocytes and is involved in transporting and removing cholesterol (Hauser et al., 2011). Furthermore, ApoE was reported to be involved in the degradation of $\mathrm{A} \beta$ (Jiang et al., 2008). Humans carry the $\varepsilon 2, \varepsilon 3$, and $\varepsilon 4$ alleles with a worldwide frequency of 8.4, 77.9 and $13.7 \%$, respectively (Liu et al., 2013). Compared with $\varepsilon 3 / \varepsilon 3, \varepsilon 4$ hetero carriers have an odds ratio (OR) of 2.8 [95\% confidence interval (CI) 2.3-3.5], whereas homo carriers $(\varepsilon 4 / \varepsilon 4)$ have an OR of 11.8 (95\% CI $7.0-19.8)$ (Pontifex et al., 2018). Conversely, APOE\&2 is considered a protective factor for $\mathrm{AD}$ symptoms and pathology (Liu et al., 2013; Jindal and Bansal, 2016). APOE\&4 has been reported to be involved in abnormal $\mathrm{A} \beta$ accumulation and perturbed functional connectivity (FC) (Sheline et al., 2010a).

Recent whole-exome sequencing and genome-wide association studies (GWAS) revealed a rare variant of the triggering receptor expressed on myeloid cells 2 (TREM2) in AD (Guerreiro et al., 2013; Jonsson et al., 2013). Interestingly, TREM2, which is expressed by microglia, could be involved in the removal of $A \beta$. It is expected that advances in genetic research will continue to reveal novel AD risk genes.

\section{Fluid Biomarkers}

$\mathrm{A} \beta$ and tau, which constitute the hallmark senile plaques and NFTs, respectively, are the most important biomarkers of $\mathrm{AD}$ (Hampel et al., 2010; Olsson et al., 2016). The Alzheimer's Disease Neuroimaging Initiative (ADNI) revealed that CSF can be used to detect the earliest changes in AD pathology (Weiner et al., 2012). Another study found decreased CSF-A $\beta$ more than 25 years before the onset of AD (Bateman et al., 2012). These findings are incorporated into clinical diagnostic criteria, such as the NIA/AA criteria, for preclinical $\mathrm{AD}$, which is the prodromal stage with normal cognition before MCI. As such, CSF-A $\beta$ is considered a promising $\mathrm{AD}$ biomarker for early diagnosis, and is widely used in both the clinical and research laboratory settings. Lower $\mathrm{A} \beta_{1-42}$ level and higher total tau (t-tau) or $\mathrm{p}$-tau are reliable
CSF biomarkers of $\mathrm{AD}$ pathology. Also, several reports suggest that the ratio of $A \beta_{1-42} / A \beta_{1-40}$ (Blennow and Hampel, 2003), $\mathrm{t}$-tau/A $\beta_{1-42}$ (Shaw et al., 2009) or p-tau/A $\beta_{1-42}$ (De Meyer et al., 2010) more accurately reflect $A D$ pathology than $A \beta_{1-42}$ or tau alone. In p-tau, CSF-tau phosphorylated at serine 181 (p-tau 181) is regarded as an AD-specific biomarker (Hampel and Teipel, 2004). As a CSF marker under development, A $\beta$ oligomers might become a useful biomarker. $A \beta$ oligomers are formed during the polymerization process of $A \beta$ fibrils and are suggested to cause synaptic dysfunction. However, a hurdle to quantitative evaluation is the limited amount of $\mathrm{A} \beta$ oligomers in CSF (Hampel et al., 2010).

It has been suggested that plasma p-tau 181 is a potential ADspecific marker for predicting neurodegeneration and cognitive decline (Barthélemy et al., 2020; Moscoso et al., 2021). The results of a meta-analysis of blood biomarkers showed increased t-tau, p-tau 181, p-tau 217, neurofilament light protein (NFL) and decreased $A \beta_{1-42}$ in patients with $\mathrm{AD}$ and $\mathrm{AD}-\mathrm{MCI}$ (Qu et al., 2021).

\section{Neuroimaging Blood Flow/Metabolism Changes}

Detecting changes in cerebral perfusion using single-photon emission computed tomography (SPECT) is widely used in the clinical field to distinguish AD from other dementias. ${ }^{18} \mathrm{~F}$ fluorodeoxyglucose positron emission tomography (FDG PET) detects patterns of regional glucose metabolism associated with $\mathrm{AD}$ pathology (neuronal loss). The core finding is similar between perfusion SPECT and FDG-PET. Decreased perfusion or glucose metabolism in the temporal lobe, the parietal lobe and the posterior cingulate gyrus (PCC) is indicative of AD (Bloudek et al., 2011). The sensitivity of perfusion SPECT to distinguish patients with $\mathrm{AD}$ from healthy subjects is $80 \%$, and the specificity is $85 \%$ (McKhann et al., 2011). FDG-PET discriminates between $\mathrm{AD}$ and healthy subjects with a sensitivity of $90 \%$ and a specificity of $89 \%$ (Bloudek et al., 2011).

\section{Amyloid Positron Emission Tomography}

Visualization of deposition of $A \beta$ or tau in the brain is strong evidence of $\mathrm{AD}$ pathology. Both amyloid-PET and tau-PET provide indispensable information for the classification and interpretation of the underlying pathophysiology as well as for the early diagnosis. Recently, the removal of $\mathrm{A} \beta$ fibrils and tau accumulation is considered a promising disease-modifying therapy, and thus the visualization of abnormal $\mathrm{A} \beta$ or tau in the brain is becoming even more important from the viewpoint of treatment. $\mathrm{A} \beta$ deposition can be visualized using PET. There are several standard probes, including Pittsburgh compound B $\left({ }^{11} \mathrm{C}-\mathrm{PiB}\right)$ and several ${ }^{18} \mathrm{~F}$ agents (florbetapir and florbetaben), for amyloid-PET (Chételat et al., 2020). ${ }^{11} \mathrm{C}-\mathrm{PiB}$ has been used as a standard PET probe for a long time and has substantially advanced our knowledge of the disease. However, because ${ }^{11} \mathrm{C}$ $\mathrm{PiB}$ has a half-life of only $20 \mathrm{~min}$, its use is limited to hospitals with a cyclotron and synthesis unit. Currently, multiple ${ }^{18} \mathrm{~F}$ probes, which have a longer half-life of $110 \mathrm{~min}$, and is thus deliverable from a factory, have been developed so that amyloidPET can be performed at more hospitals than before. 
Both CSF-A $\beta$ and amyloid-PET are tests for identifying $\mathrm{AD}$ pathology related to senile (amyloid) plaques. In a report comparing PiB-PET and CSF biomarkers, PiB-positive patients had significantly lower $\mathrm{A} \beta$ and significantly higher $\mathrm{t}$-tau and p-tau in CSF compared with PiB-negative subjects (Shimada et al., 2011). There is a negative correlation between PET A $\beta$ levels and CSF A $\beta$ levels. The diagnostic value of amyloidPET and CSF-A $\beta$ is comparable, but they differ slightly in the information they provide. Unlike CSF-A $\beta$, amyloid-PET can visualize the spatial extent of amyloid deposition. In $\mathrm{AD}$, the core imaging findings are amyloid accumulation in the frontal lobe, PCC and precuneus. The amyloid burden in these regions can explain the pathophysiology of $\mathrm{AD}$ well and can provide a key to differential diagnosis from other dementias. PET probe injection is less invasive than a lumbar puncture, so that cognitively healthy people may undergo amyloid-PET more comfortably than CSF collection for screening or possibly prodromal interventions. Conversely, CSF-A $\beta$ is suggested to reflect $\mathrm{AD}$ pathology earlier than amyloid-PET (Mattsson et al., 2015). Even if amyloid-PET is negative, CSF measurements may identify earlier amyloid pathology. Furthermore, if a promising CSF biomarker is developed in the future (Hampel et al., 2010), additional tests can be performed if the frozen CSF sample is preserved. Thus, past patient conditions can be evaluated using the latest testing method with CSF. CSF and amyloid-PET are thus complementary, and it is important to combine the two tests to assess amyloid pathology more comprehensively than before.

\section{Tau Positron Emission Tomography}

Although tau-PET has faced some problems, such as difficulty in developing a probe with a high affinity for $\mathrm{AD}$-tau and a low affinity for $A \beta_{1-42}$ (Valotassiou et al., 2018), multiple nuclides, including ${ }^{11} \mathrm{C}-\mathrm{PBB} 3 /{ }^{18} \mathrm{~F}-\mathrm{PM}-\mathrm{PBB}$ (Maruyama et al., 2013; Tagai et al., 2021) and ${ }^{18}$ F-flortaucipir (Leuzy et al., 2019) are now available. The intracerebral accumulation rate of tau-PET nuclides correlates well with the severity of the disease. Therefore, it attracts attention as a modality with favorable characteristics compared with other biomarker candidates (Joie et al., 2020).

Tau-PET is a promising imaging method for the diagnosis of various neurodegenerative disorders including the $\mathrm{AD}$ spectrum. Amyloid burden visualized by PET is affected by aging and the ApoE allele, and hence the specificity of $\mathrm{AD}$ diagnosis with amyloid PET is relatively low especially in the elderly aged over 80 years old (Ossenkoppele et al., 2015). Contrastingly, tau-PET has been reported to show high specificity in differentiating $\mathrm{AD}$ from other neurodegenerative disorders (Ossenkoppele et al., 2018). Moreover, tau-PET positivity can be a better predictor of cognitive decline in AD as compared with CSF-p-tau 181 or amyloid PET (Bucci et al., 2021). Another study using ${ }^{11} \mathrm{C}$ PBB3 PET revealed cases with tau accumulation without $\mathrm{A} \beta_{1-42}$ accumulation by amyloid-PET (Shimada et al., 2017). This amyloid-negative and tau-positive state may represent an entity called primary age-related tauopathy (PART) (Crary et al., 2014). Dementia with PART overlaps with senile dementia of the NFT type (SD-NFT), which is tau-related dementia distinct from AD. Patients with SD-NFT are sometimes misdiagnosed as AD, and hence tau-PET may be useful for differential diagnosis.
The PET can provide data most closely related to the neuropathological diagnosis. Yet, PET is an expensive tool and thus may not be affordable in many places in the world. Therefore, early biomarkers using relatively easy-toperform tests, such as blood tests and magnetic resonance imaging (MRI), should be explored. Until such surrogate markers become available, PET will remain one of the most important tools in cohort studies of neurodegenerative disorders. In the meantime, it is important to organize comprehensive and high-quality cohort studies to acquire multiple PET scan along with fluid samples (both blood and CSF) and MRI.

\section{Structural Magnetic Resonance Imaging}

Hippocampal and MTL atrophy in structural MRI is frequently used as an adjunct to clinical diagnosis of $\mathrm{AD}$. In a systematic review, MTL atrophy was discriminative between $\mathrm{AD}$ and healthy persons with a sensitivity of $85 \%$ and a specificity of $88 \%$ (Scheltens et al., 2002). In $\mathrm{AD}$, the accumulation of $\mathrm{A} \beta_{1-42}$ and $\mathrm{p}$-tau is thought to become saturated before the onset of symptoms such as cognitive decline and cerebral atrophy, which become apparent later (Weiner et al., 2015). Reflecting this time course, changes in brain structure occur mainly after the onset of cognitive decline, and therefore, structural MRI primarily provides imaging markers for diagnosis and severity assessment after onset.

Reduced hippocampal volume is a consistent finding across structural MRI studies as previously observed in postmortem brains. A voxel-based morphometry (VBM) analysis of structural MRI suggested that the progression of cerebral atrophy in $\mathrm{AD}$ parallels the putative propagation of neurofibrillary tangle implicated by Braak staging (Matsuda, 2016). A combining a neuropsychological battery with VBM analysis of MRI data from ADNI found correlations between memory loss and mediolateral temporal lobe atrophy as well as between executive dysfunction and parietotemporal atrophy (Nho et al., 2012). White matter changes in $A D$ are reported to be less significant than gray matter changes. However, a metaanalysis of VBM suggests that in patients with $\mathrm{AD}$, there is considerable volume loss in the white matter beneath the parahippocampal gyrus and in the posterior corpus callosum (Matsuda, 2016).

\section{Diffusion Tensor Imaging}

Tau is a microtubule-associated protein that is involved in stabilizing the microtubule structure of neuronal axons (Guo et al., 2017). DTI is a method for capturing changes in the microstructure of the white matter, and it may be able to detect axonal changes related to tau pathology. In $\mathrm{AD}$, reduced fractional anisotropy (FA) is most pronounced in fiber tracts in the limbic area, such as the fornix, and in the temporal lobe (Teipel et al., 2015). This abnormality in white matter microstructure is an early change seen in the process of $\mathrm{AD}$ neurodegeneration. Moreover, an FA reduction in PCC has been reported in patients in the prodromal stage, 
including subjective cognitive impairment (SCI) and mild MCI (Stenset et al., 2011).

\section{Functional Magnetic Resonance Imaging}

Functional MRI can be used to observe brain activities noninvasively via blood-oxygen-level-dependent (BOLD) signals, which reflect local fluctuations in the oxygenation of cerebral blood (Ogawa et al., 1990). Task-related changes in BOLD signals and synchronous BOLD fluctuations across multiple regions at resting state exhibit changes associated with the onset and progression of neurodegenerative diseases, including AD. In fMRI studies with a memory task, patients with early MCI show increased activation in the MTL (Dickerson et al., 2004, 2005; Chhatwal and Sperling, 2012) and hippocampus (Celone et al., 2006), compared with healthy controls. This hyperactivation may be lost at follow-up (O'Brien et al., 2010; Bai et al., 2011). Therefore, it is hypothesized that temporary hyperactivation is a compensatory mechanism in the early stage of AD (Clment and Belleville, 2010).

Resting-state functional connectivity MRI (rsfcMRI) is a promising imaging modality for pre-symptomatic diagnosis of AD. This type of MRI focuses on the co-fluctuation of BOLD signals across brain regions in the low-frequency band below $0.1 \mathrm{~Hz}$ (Liu, 2013). Thus, rsfcMRI studies assume that brain regions with mutually interwoven networks should show similar fluctuations in low-frequency BOLD signals, reflecting concerted fluctuation of synaptic activity propagated through the neural network. Another assumption is that the level of coordination of signals across brain regions reflect specific functions subserved by the network. Interestingly, FC can be detected between regions without known direct fiber connections (Honey et al., 2009), meaning that rsfcMRI may detect network abnormalities that cannot be discovered by studies of structural connectivity. Thus, rsfcMRI is valuable as a biomarker of $\mathrm{AD}$ because brain networks are differentially affected by various factors, including the stage of the disease (Wang et al., 2006; Sheline and Raichle, 2013; Kim et al., 2015; Córdova-Palomera et al., 2017; Palmqvist et al., 2017), symptoms (Adriaanse et al., 2014), treatments (Ochmann et al., 2017), pathology (Sheline et al., 2010a,b; Robinson et al., 2017; Shi and Holtzman, 2018) and genetic factors (Vöglein et al., 2019). In $\mathrm{AD}$, various types of network alterations, including those of the default mode network (DMN), are reported (Figure 1A).

The most well-established finding is that hippocampal-default mode network (DMN) connectivity is reduced compared with healthy people (Hohenfeld et al., 2018). Among the nodes within the DMN, the importance of connectivity between the precuneus and PCC has been demonstrated in numerous studies (Greicius et al., 2003; Wu et al., 2011; Teipel et al., 2015; Palmqvist et al., 2017; Ibrahim et al., 2021). The precuneus plays a central role in visuospatial imagery, episodic memory retrieval, and processing of self-related information (Cavanna and Trimble, 2006). The PCC is related to internally-directed thinking and helps allocate attention efficiently in collaboration with the ECN (Leech et al., 2011). Abnormal connectivity between the PCC and precuneus likely reflects pathological changes in $\mathrm{AD}$ as substantial abnormalities are detected in these regions, such as decreased glucose metabolism and perfusion, and accumulation of abnormal proteins (Bloudek et al., 2011; Daerr et al., 2017). Indeed, the FC abnormality in AD is, at least in part, associated with amyloid accumulation. Changes in $\mathrm{AD}$-like connectivity have been found in amyloid-positive non-AD patients (Sheline et al., 2010b). Surprisingly, APOE\&4 carriers have reduced connectivity at the stage of no amyloid accumulation (Sheline et al., 2010a).

The pattern of DMN FC abnormality may depend on the age of onset. Early-onset AD shows impairment among a wide range of connectivities, including visual network, auditory network, sensorimotor network (SMN), DMN, executive control network $(\mathrm{ECN})$, and dorsal attention network (DAN), compared with senile-onset AD (Adriaanse et al., 2014).

Several rsfcMRI studies have attempted to classify categories within the $\mathrm{AD}$ spectrum (e.g., $\mathrm{AD}-\mathrm{MCI}$ vs. $\mathrm{AD}$ ), $\mathrm{AD}$ from other dementia spectra, or from healthy elderlies (Zhou et al., 2010; Wee et al., 2016; Zhang et al., 2019). Conventional static FC, dynamic FC (reflecting changes in FC over time), and amplitude of low-frequency fluctuations (ALFF) have been used for classification. The combination of these different modalities slightly improves classification accuracy (de Vos et al., 2018). Machine learning (ML) classification using PCCFC can classify $\mathrm{AD}$ and healthy elderlies with a sensitivity of $75.2 \%$ and a specificity of $74.9 \%$ (Ibrahim et al., 2021). The ICA-based ML technique can classify $\mathrm{AD}$ patients and healthy elderlies with a sensitivity of $78.2 \%$ and a specificity of 83.2\% (Ibrahim et al., 2021). In classifying $\mathrm{AD}$ patients from healthy elderlies, the classification performance is significantly improved when multiple MR modalities (structural MRI, DTI, and $\mathrm{rsfMRI}$ ) are combined, compared with a single imaging modality (Schouten et al., 2016).

\section{PARKINSON'S DISEASE}

The core condition of the LBD/PD spectrum, $\mathrm{PD}$, is the most common movement disorder and is caused primarily by the loss of nigrostriatal dopaminergic neurons, associated with the intracellular deposition of $\alpha$-syn (Postuma et al., 2015). The cardinal clinical symptom is a movement disorder comprehensively called parkinsonism, with features of akinesia, rigidity, resting tremor, and postural instability. The PD spectrum may also present with cognitive disturbance and dementia. In $\mathrm{PD}$, the prevalence of $\mathrm{MCI}$ is reported to be $40 \%$ (Baiano et al., 2020), and that of dementia is 30\% (Hanagasi et al., 2017). Dementia in PD spectrum is characterized by hallucination with highly specific content and temporal fluctuations in cognitive function centered on attention and arousal (Dickson et al., 2017). DLB is diagnosed if dementia is already present from the onset, and PD with dementia (PDD) is diagnosed if cognitive decline occurs after the onset of motor symptoms. In general, 1 year after the onset of PD is used as the boundary between PDD and DLB (1-year rule) (Bonanni et al., 2006; McKeith et al., 2017). Thus, PDD and DLB may constitute a spectrum (Jellinger and Korczyn, 2018). Some reports indicate differences in clinical features between PDD and DLB. Patients with DLB tend to have severer visuospatial cognitive, executive, and attentional decline 

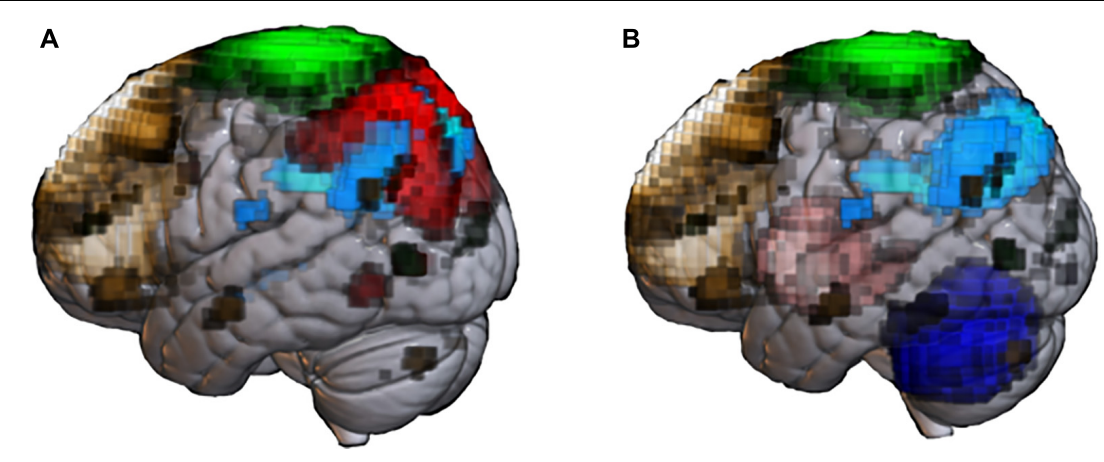

FIGURE 1 | Abnormal resting-state networks in Alzheimer's disease (AD) and Parkinson's disease (PD). Functional network templates were extracted from the MRI database (70 healthy elderly) at the National Center of Neurology and Psychiatry' to display network abnormality reported in past AD (A) and PD (B) studies.

(A) Default mode network (DMN, light blue) is the representative network impaired in patients with senile-onset AD. Early- onset AD shows impaired not only DMN, but also executive control network (brown), sensory-motor network (SMN, green) and dorsal-attention network (red). (B) Patients with PD shows extensive network impairment, including basal ganglia (pink), cerebellum network (blue), and SMN. PD patients with cognitive impairment shows impaired DMN and ECN.

than people with PDD (Morra and Donovick, 2014). In terms of the motor symptoms, resting tremor and laterality are less evident in DLB than in PDD.

Symptoms common in $\mathrm{AD}$, including olfactory dysfunction, apathy, and anxiety depression, are also common in dementia in the PD spectrum (Attems et al., 2014; Le Heron et al., 2018; Galts et al., 2019). As described later, DLB/PDD is associated with various degrees of $\mathrm{AD}$ pathology, and this shared pathology may be the reason for the clinical similarity between $\mathrm{AD}$ and PDD/DLB.

\section{Diagnostic Criteria}

There are two widely used diagnostic criteria for PDthe United Kingdom Parkinson's Disease Society Brain Bank (UKPDSBB) clinical diagnostic criteria (Gibb and Lees, 1988; Hughes et al., 1992) and the International Parkinson and Movement Disorder Society (MDS) clinical diagnostic criteria for PD (Postuma et al., 2015). Both require bradykinesia as a core symptom.

UKPDSBB criteria diagnose PD with the following three steps: presence of parkinsonism (step 1), exclusion of other parkinsonian syndromes (step 2), and existence of supportive features (step 3). These criteria are used worldwide and have had their accuracy verified by postmortem pathological diagnoses. The MDS diagnostic criteria include criteria for clinical diagnosis and research criteria for probabilistic prediction of PD before the diagnosis, according to risk factors and mild symptoms. Multiple studies have reported a high concordance rate for PD diagnosis between UKPDSBB criteria and MDS criteria (Malek et al., 2017; Postuma et al., 2018). Neither criterion mentions PDD, which requires an independent assessment (Sachdev et al., 2014).

\section{Motor and Neuropsychological Tests}

In the PD spectrum, the MDS-Sponsored Revision of the Unified Parkinson's Disease Rating Scale (MDS-UPDRS) is widely used for the evaluation of motor and non-motor symptoms (Goetz et al., 2008). MDS-UPDRS is divided into the following four sections: questionnaire for non-motor symptoms in daily life (Part 1), motor symptoms in daily life (Part 2), motor examination by a physician (Part 3), and questionnaire for motor complications (Part 4). The score is used for evaluation of disease severity and response to treatment.

Because of the difference in clinical symptoms, PD has been traditionally subjected to neuropsychological tests slightly different from those for $\mathrm{AD}$. A condition consistent with MCI is found in nearly half of people with PD (Goldman et al., 2018). A longitudinal study reported that $80 \%$ of people with PD eventually show dementia (Williams-Gray et al., 2007). In PD, executive function is particularly vulnerable. Executive dysfunction is found from the prodromal stage and is more pronounced than memory impairment. Therefore, in the cognitive evaluation of PD, a test of frontal lobe functions such as Frontal Assessment Battery (FAB) (Dubois et al., 2000) is often added to a general cognitive test such as MMSE. Otherwise, it is recommended to perform MoCA, in which executive functions are tested in more detail than MMSE (Weintraub et al., 2015).

To assess cognitive dysfunctions in early PD (such as PD$\mathrm{MCI}$ ), it is recommended to examine five cognitive domainsmemory, executive, attention/working memory, language, and visuospatial function (Litvan et al., 2012). To this end, thorough testing with WAIS and WMS may be considered (Tang et al., 2016).

In PDD, psychiatric symptoms are often directly linked to a decrease in Activities of Daily Living (ADL), and it is essential to evaluate the severity of psychiatric symptoms properly (Rosenthal et al., 2010). MDS-UPDRS Part 1 evaluates these symptoms. Questionnaires such as Beck Depression Inventory (BDI) (Beck et al., 1961), Questionnaire for ImpulsiveCompulsive Disorders (QUIP) (Probst et al., 2014), and StateTrait Anxiety Inventory (STAI) (Caillava-Santos et al., 2015) are often used for the assessment of psychiatric symptoms in the PD spectrum.

\section{Genetics}

Like $\mathrm{AD}, \mathrm{PD}$ is primarily a sporadic disease. Multiple genetic and environmental factors appear to be involved in the onset of 
PD. Approximately 5\% of PD cases are familial, some of which are inherited in a Mendelian fashion, including SNCA, PKRN, and LRRK2 (Singleton and Hardy, 2019). Studies of PD genetics have revealed some of the mechanisms including abnormal $\alpha$-syn deposition, oxidative stress, mitochondrial dysfunction, and abnormalities in the ubiquitin-proteasome system leading eventually to cell death (Ganguly et al., 2021). Genomewide association studies (GWASs) have identified many single nucleotide polymorphisms (SNPs) as risk factors for PD (Nalls et al., 2014; Blauwendraat et al., 2020). However, it is still unclear how and to what extent each of these genes is related to $\mathrm{PD}$ pathology.

$G B A$ has recently been recognized as a risk gene for PD. $G B A$ is the causative gene of Gaucher's disease, an autosomal recessive lysosomal disorder caused by glucocerebrosidase (GBA) deficiency (Hruska et al., 2008). It is reported that decreased GBA activity increases soluble $\alpha$-syn oligomers (Mazzulli et al., 2011). Interestingly, decreased GBA activity in the brain is also seen in patients with sporadic PD (Gegg et al., 2012). The OR for any $G B A$ mutation in PD patients vs. controls was reported to be 5.43 (Sidransky et al., 2009). Carriers of GBA mutations are reported to represent $4-29 \%$ of patients with $\mathrm{PD}$, and $G B A$ may be related to the early onset of PD (Lees et al., 2009).

\section{Fluid Biomarkers}

There are few established serum biomarkers for PD. However, several reports have pointed out the association between $\mathrm{PD}$ and inflammatory markers. For example, a study found a correlation between the development of sporadic PD and elevated inflammatory biomarkers such as serum TNF- $\alpha$ and IL6 (Ferrari and Tarelli, 2011). Another study found that decreased apolipoprotein A1 and increased C-reactive protein (CRP) were associated with severe motor symptoms, depression, and sleep disorders (Ferrari and Tarelli, 2011; Lawton et al., 2020).

The most straightforward fluid biomarker should be the direct measurement of $\alpha$-syn. However, there are some difficulties in measuring the protein in body fluids. Blood has the advantage of easy collection, but simple measurement of $\alpha$-syn using a blood sample is not currently helpful in distinguishing PD from healthy population. Although there are multiple reports of elevated plasma or serum $\alpha$-syn levels in PD patients compared with healthy people (Chang et al., 2020), reports on the correlation between $\alpha$-syn levels and clinical symptoms are inconsistent. There is even a report of decreased plasma a-syn in PD patients ( $\mathrm{Li}$ et al., 2007). Technical problems may underlie the discrepancies, including contamination of $\alpha$-syn from erythrocytes due to hemolysis, differences in assay technique, and differences in the binding ability of the antibodies to $\alpha$-syn (Ganguly et al., 2021). More recently, $\alpha$-syn oligomers and aggregated $\alpha$-syn have drawn attention as biomarkers for the progression of PD (Maass et al., 2019). The $\alpha$-syn oligomers and aggregated $\alpha$-syn may be involved in the transcellular transmission of $\alpha$-syn (Okuzumi et al., 2021).

Measurement of $\alpha$-syn in CSF should be established. Many studies have reported that total $\alpha$-syn is lower in patients with PD than in healthy controls (Tokuda et al., 2006; Mollenhauer et al., 2013; Wennström et al., 2013). However, the specificity of this finding is not high enough to distinguish $\mathrm{PD}$ from healthy controls or from other parkinsonian syndromes (Zhou et al., 2015). Measurement of phosphorylated $\alpha$-syn or the ratio of phosphorylated $\alpha$-syn to total $\alpha$-syn might be helpful in distinguishing PD from healthy controls and from other parkinsonian syndromes (Majbour et al., 2016). CSF studies also show an increase in $\alpha$-syn oligomers and an increase in the ratio of $\alpha$-syn oligomer to total $\alpha$-syn in PD (Tokuda et al., 2010; Majbour et al., 2016; Kakuda et al., 2019). The development of measurement methods has seen recent progress (Kakuda et al., 2019; Okuzumi et al., 2021). Recently, real-time quaking-induced conversion (RT-QuIC), a technique originally developed to detect the self-aggregating ability of proteins in prion diseases, was used for detecting $\alpha$-syn aggregation with a sensitivity of 92\% (DLB) and $95 \%$ (PD), and a specificity of 100\% (Fairfoul et al., 2016). The use of the novel assays, including RT-QuIC and $\alpha$-syn oligomers, currently promises the most useful biomarker to precisely capture synuclein deposition.

\section{Neuroimaging \\ Blood Flow/Metabolism Changes}

Changes in cerebral perfusion are used primarily for the auxiliary diagnosis of PDD. Using SPECT, decreased perfusion is observed along with disease progression and impaired cognitive function in patients with PDD. In particular, perfusion in the frontal, parietal and occipital lobes is reduced in patients with PDD (Spampinato et al., 1991; Sawada et al., 1992). Furthermore, in PDD patients with impaired visual cognitive function, decreased perfusion in the occipital lobe is remarkable (Abe et al., 2003). In FDG-PET, glucose hypermetabolism is observed mainly in the putamen, motor cortex and cerebellum, and hypometabolism is seen in the posterior temporoparietal and occipital lobes (Meyer et al., 2017; Thobois et al., 2019). An FDG-PET study revealed that DLB had higher glucose metabolism in PCC and precuneus than did $\mathrm{AD}$, irrespective of amyloid deposition (Graff-Radford et al., 2014).

\section{Positron Emission Tomography/Single-Photon Emission Computed Tomography to Detect Monoaminergic Dysfunction in Parkinson's Disease Spectrum}

Single-photon emission computed tomography can visualize PD-derived neurodegeneration, such as the reduction in dopaminergic nerve endings and the loss of the epicardial sympathetic nerve.

${ }^{123}$ I-meta-iodobenzylguanidine (MIBG)-SPECT captures the loss of postganglionic sympathetic neurons in the PD spectrum. It was reported that abnormalities in ${ }^{123}$ I-MIBG-SPCET could be diagnostic in PD, with a sensitivity of $84.3 \%$ and a specificity of $89.5 \%$ (Sawada et al., 2009). ${ }^{123}$ I-MIBG-SPECT abnormality can be observed at the early stages, even before the onset of definitive motor symptoms in PD (Heinzel et al., 2019). However, it should be noted that some patients can show a false negative finding in the early stages (Sawada et al., 2009).

Presynaptic dopaminergic neuronal loss can be detected using dopamine transporter (DAT)-SPECT. Of the many radiotracers, ${ }^{123}$ I-Ioflupane is the easiest to access. There are multiple reports 
that the sensitivity and specificity for loss of dopaminergic nerve terminals using DAT-SPECT are 90\% or higher (Pirker, 2003; Brigo et al., 2014; O’Brien et al., 2014). Still, false-negative cases have been pointed out ( $\mathrm{Ba}$ and Martin, 2015). Although it is challenging to distinguish PD from other parkinsonian syndromes using the results from DAT-SPECT only, some studies reported that visual inspection and evaluation of specific binding ratio (SBR) over time can help distinguish PD from other synucleinopathies (Sakakibara et al., 2020). It has been reported that the combined use of DAT-SPECT and MIBG SPECT enhances the specificity of the diagnosis of PD (Yoshii et al., 2017). Therefore, if clinical diagnosis of PD is challenging, the combined use of DAT-SPECT and MIBG SPECT may be considered. Semi-quantified values are available in the form of heart-mediastinal ratio in MIBG-SPECT and SBR of DATSPECT. Furthermore, a correction method of these values across different facilities has been proposed for multicenter research (Nakajima et al., 2012; Matsuda et al., 2018).

\section{Positron Emission Tomography to Detect Abnormal Protein Deposition in Parkinson's Disease Spectrum}

The PET imaging technology for visualizing $\alpha$-syn accumulation has not been established yet (Verdurand et al., 2018). Several PET tracers are under development, and animal experiments have confirmed the affinity of the tracers for $\alpha$-syn aggregates (Kuebler et al., 2021). If an $\alpha$-syn tracer is developed for humans, it will be possible to identify patients in the preclinical/prodromal stage, to evaluate changes in $\alpha$-syn deposition in the course of disease progression, and to distinguish PD from other parkinsonian syndromes. Further research and development are urgently needed.

In terms of $A \beta /$ tau accumulation, patients with PDD/DLB have many similarities with $\mathrm{AD}$ from multiple perspectives. In a cross-sectional amyloid PET study, PDD and DLB showed moderate to prominent amyloid burden in most cases whereas PD with normal cognition had little amyloid burden (Mashima et al., 2017). The spatial distribution of amyloid in PDD/DLB was similar to that in AD (Shimada et al., 2013). It was also reported that the uptake pattern of tau PET tracer in the temporal-lobe is different between AD and DLB (Kantarci et al., 2017). This discrepancy between PDD/DLB and AD is still under investigation and is going to be discussed in detail in the UNRESOLVED QUESTIONS AND FUTURE DIRECTIONS section.

\section{Structural Magnetic Resonance Imaging}

Previously in the PD research, structural MRI was performed only to rule out other parkinsonian syndromes such as vascular parkinsonism. This poor performance was partly due to the difficulty in detecting PD-specific structural abnormalities using conventional sequences with low-field MRI imaging below 1.5 $\mathrm{T}$ (Sterling et al., 2016). With a higher magnetic field of $3 \mathrm{~T}$, group-level analyses revealed a loss of volume in the putamen (Tinaz et al., 2011), midbrain, basal ganglia, basal forebrain and medial temporal lobe (Zeighami et al., 2015), occipital lobe and head of the caudate nucleus (Sterling et al., 2013; Lewis et al., 2016). As symptom-structure correlates, motor symptoms have been associated with frontal lobe atrophy (Burton et al., 2004; Rosenberg-Katz et al., 2013), and occipital lobe atrophy with hallucinations (Pagonabarraga et al., 2014). Cognitive impairment is related to atrophy of widely distributed structures (Zeighami et al., 2019), including the hippocampus (Laakso et al., 1996; Camicioli et al., 2003; Junqué et al., 2005; Tam et al., 2005; Ibarretxe-Bilbao et al., 2008), the anterior cingulate cortex (Nagano-Saito et al., 2005), the temporal cortex (Summerfield et al., 2005), the frontal cortex (Burton et al., 2004; Nagano-Saito et al., 2005), and the parietal cortex (Sanchez-Castaneda et al., 2009).

The substantia nigra pars compacta $(\mathrm{SNc})$, where the cell bodies of the nigrostriatal dopamine neurons reside, is critical in the clinical evaluation of PD. Recently, technology with high-field MRI of $3 \mathrm{~T}$ or higher has allowed visualization of pathological processes in the SNc (Wang et al., 2016). For the assessment of the SNc, susceptibility-weighted imaging (SWI), quantitative susceptibility mapping (QSM) and neuromelanin (NM) imaging may have a diagnostic value. SWI is sensitive to the iron content in the brain. In patients with $\mathrm{PD}$, iron is accumulated in the brain; therefore, iron-deposition imaging may be useful. SWI studies suggest that iron deposition is higher in patients with PD than in healthy people in the $\mathrm{SNc}$, caudate nucleus, red nucleus, putamen and globus pallidus (Zhang et al., 2009; Wu et al., 2014; Wang et al., 2016). QSM is another iron mapping technique through the modeling of magnetic susceptibility sources. QSM studies indicate increased iron deposition in the SNc (Ahmadi et al., 2020; Poston et al., 2020), red nucleus (Cheng et al., 2020), prefrontal cortex, caudate (Chen et al., 2019) and putamen (Thomas et al., 2020) in PD. In a meta-analysis of the iron deposition imaging in $\mathrm{PD}$, iron deposition in the SNc was shown with both SWI and QSM. Moreover, positive correlation between QSM iron deposition and the total UPDRS score has been reported (Pyatigorskaya et al., 2020).

Neuromelanin-contrast MRI might provide a promising biomarker for the PD spectrum. NM is present in dopaminergic neurons in the SNc. Turbo spin echo T1-weighted MRI sequence with magnetization transfer (Sasaki et al., 2008) and gradient recalled echo with magnetization transfer (van der Pluijm et al., 2021) are currently used to yield a contrast sensitive to NM. NM MRI signals increase with age in the healthy population, but are markedly decreased in $\mathrm{PD}$, reflecting the loss of dopamine neurons (Sasaki et al., 2008; Zucca et al., 2014).

\section{Diffusion Tensor Imaging}

In PD, many studies have reported correlations between decreased FA in the SN and severe motor symptoms (Prakash et al., 2012; Schuff et al., 2015; Langley et al., 2016). FA abnormalities have been reported also for non-motor symptoms, and these are associated with cognitive symptoms, mood disorders, hyposmia, hallucinations, and REM sleep behavior disorder (RBD) (Hall et al., 2016).

Patients with PDD show decreased FA and increased mean diffusivity throughout the cerebral white matter compared with healthy people (Melzer et al., 2013). Reduced hippocampal FA is also reported in patients with PDD compared with patients with 
PD and those with normal cognitive functions (Chen B. et al., 2015). Others have reported an association of general cognitive decline evaluated by MMSE and MoCA with lower FA in the corpus callosum, the anterior cingulate cortex, and the frontal white matter regions (Kamagata et al., 2012; Chen B. et al., 2015).

\section{Functional Magnetic Resonance Imaging}

In $\mathrm{PD}$, various alterations are reported in motor-related restingstate networks, including the basal ganglia (Helmich et al., 2010; Hacker et al., 2012; Agosta et al., 2014; Rolinski et al., 2015), cerebellum (Hu et al., 2015; O'Callaghan et al., 2016) and SMN (Fling et al., 2014; Bell et al., 2015; Canu et al., 2015) (Figure 1B). A meta-analysis suggests that decreased FC in the posterior putamen in PD may be a consistent finding (Herz et al., 2014).

Changes in FC may reflect a specific type of motor symptom. Tremor-dominant PD patients, compared with patients without tremor, show increased FC within the striatum (Dirkx et al., 2016), between the subthalamic nucleus and motor and primary somatosensory cortices (Baudrexel et al., 2011), and among the cerebellum, thalamus and motor cortex (Helmich et al., 2011). Nevertheless, decreased FC in tremor-dominant PD has also been reported in the cerebellum ( $\mathrm{Hu}$ et al., 2015), putamen (Chen H.M. et al., 2015) and primary somatosensory cortex (Zhang et al., 2015). Akinetic-rigid subtype patients, compared with healthy controls, show increased FC in the left putamen, bilateral angular gyri, bilateral medial prefrontal cortices (MPFC) (Zhang et al., 2015) and anterior DMN (Hou et al., 2018b), while they show decreased FC in the precuneus, amygdala (Guan et al., 2017), the left inferior parietal cortex and PCC within the DMN (Karunanayaka et al., 2016; Hou et al., 2018b), and the precentral gyrus (Hu et al., 2015). In summary, the akinetic-rigid subtype shows more widespread alterations in FC, especially in the DMN, compared with the tremor-dominant subtype. This finding may be related to the observation that patients with the akinetic-rigid subtype are more likely to develop cognitive impairment than those with the tremor-dominant subtype (Karunanayaka et al., 2016). Freezing of gait (FOG) is a PD-related gait disturbance characterized by sudden and temporary inability to walk forward or turn (Vandenbossche et al., 2012). A study reported a correlation between severer FOG and lower FC in the SMN (Canu et al., 2015) whereas another study showed increased FC in the SMN in patients with PD-FOG (Fling et al., 2014).

Functional connectivity alterations in PD vary depending on the disease stage. Patients with early drug-naive PD show altered functional connectivity in the cerebello-thalamo-cortical network (Hou et al., 2018a). Similar changes were reported in several prodromal PD studies before the onset of motor symptoms (Rolinski et al., 2016; Yamada et al., 2019; Wakasugi et al., 2021). Focusing on the subsequent changes over time in disease progression, it has been reported that the temporal progression of PD motor symptoms is correlated with reduced FC between the anterior putamen and the midbrain and increased FC between the cerebellum and the motor cortex (Manza et al., 2016). Furthermore, a study suggested that advanced PD patients may show decreased FC between the putamen, caudate and midbrain (Hacker et al., 2012). In terms of treatment, it is known that levodopa, the most commonly used medication for PD, increases motor network connectivity, which is opposite to the changes associated with the progression of motor symptoms in PD (Wu et al., 2009; Esposito et al., 2013; Agosta et al., 2014). A relationship between FC and cognitive symptoms has also been reported.

Patients with PDD show impaired FC of the DMN, compared with PD patients without dementia and healthy participants (Gorges et al., 2015). Decreased DMN-FC in PDD was also reported in a meta-analysis (Wolters et al., 2019). Patients with PDD also showed decreased ECN-FC (Filippi et al., 2019), and similar abnormality was reported at the prodromal stage (Wakasugi et al., 2021) (Figure 1B). Further reports showed disrupted connectivity in the frontoparietal network (Amboni et al., 2015; Borroni et al., 2015) and dorsal attention network (Baggio et al., 2015) in PDD. While a correlation between FC reduction in motor networks and reduced $\alpha$-syn in the CSF has been reported (Campbell et al., 2015), this finding should be interpreted with caution because reliable CSF biomarkers for PD are not yet established.

In summary, rsfcMRI studies in PD have yielded some consistent findings, such as decreased FC in the putamen in most PD cases and DMN in cognitively impaired PD cases. Further research is needed to clarify the connectivity changes in many other networks, particularly as the observed connectivity changes in a particular network differ among reports. This inconsistency in FC findings may be caused by differences in the predominant clinical symptoms and disease stage (Hohenfeld et al., 2018; Filippi et al., 2019; Wolters et al., 2019). In this regard, it remains unclear if increases in FC reflect a compensatory mechanism or pathological processes. The inconsistency among previous rsfMRI studies may also be ascribed to technical issues: insufficient pre-processing, modulation of FC by medications including levodopa (Tahmasian et al., 2015), and insufficient sample size (Chen et al., 2018). These problems should be overcome by accumulating high-quality rsfMRI data with sufficiently large sample size, followed by cutting-edge preprocessing such as Human Connectome Project (HCP)-style MRI protocol (Glasser et al., 2016) and the adjustment of medication.

\section{Summary}

Till now, $\mathrm{AD}$ and $\mathrm{PD}$ have been studied independently, and most findings have been obtained independently.

In $\mathrm{AD}$, memory impairment identified by clinical interview and neuropsychological testing is the core clinical symptom. Responsible genes for familial cases and risk genes for sporadic cases have been found, but more are yet to be identified. The identification of reliable biological or imaging markers for sporadic cases is of great importance in AD research to advance the development of disease-modifying therapies. Blood biomarkers are under development, and promising methods have been reported (Nakamura et al., 2018). Measurements of CSF can reveal alterations in key proteins ( $\mathrm{A} \beta$ and tau) underlying $\mathrm{AD}$ pathology. To visualize the spatial distribution of $A \beta$, amyloid-PET has been established for its utility in 
clinical studies. A few tracers have been proposed for tauPET. Structural MRI and perfusion SPECT/FDG-PET are used to detect brain atrophy and reduced blood flow/energy requirement, respectively, both of which indicate neuronal loss. The analysis of brain connectivity by rsfcMRI consistently shows abnormality in the DMN. Moreover, ML combined with FC has permitted discrimination between $\mathrm{AD}$ and healthy controls with a degree of accuracy.

Parkinson's disease is characterized by movement disorder possibly complicating cognitive impairment. In cognitive disturbance in $\mathrm{PD}$, executive function is particularly impaired. Many responsible genes for familial cases and risk genes for sporadic cases have been identified. MIBG-SPECT and DATSPECT are widely performed to detect the neurodegeneration of monoaminergic neuronal systems, which is a hallmark of PD pathology. Structural MRI with high magnetic field has utility in PD research for revealing the iron deposition and neurodegeneration in the $\mathrm{SNc}$, which are the core pathological changes in PD. Detection methods for the other pathological hallmark, $\alpha$-syn, are not established yet. Imaging measures of brain atrophy and blood flow/energy requirement show variable findings, depending in part on the motor subtype and presence of cognitive decline. Decreased perfusion is shown by SPECT in PD with cognitive decline. A group analysis using structural MRI revealed cerebral atrophy, especially in patients with substantial non-motor symptoms. Many rsfcMRI studies are reported, but again, the results vary, depending on the subtype and stage. Yet, network abnormalities of the basal ganglia, frontal lobe, and cerebellum, corresponding to movement disorders, and DMN/frontal lobe abnormalities corresponding to cognitive disorders have been consistently reported.

Because $\mathrm{AD}$ and $\mathrm{PD}$ are regarded distinct and independent disorders with different core clinical symptoms (cognitive vs. motor), different neuropsychological tests and imaging methods have been traditionally applied to each disease. Unfortunately, different evaluation methods have been applied to symptoms common to $\mathrm{AD} / \mathrm{PD}$ as well, including cognitive and psychiatric symptoms. Therefore, it remains unclear which pathophysiological mechanisms are common, and which are unique to each disorder, despite the shared symptoms and the putatively common pathological mechanisms.

\section{UNRESOLVED QUESTIONS AND FUTURE DIRECTIONS}

Research on $\mathrm{AD}$ and $\mathrm{PD}$ has substantially progressed in the last few decades, but major questions remain unresolved. Given the overlaps between $\mathrm{AD}$ and $\mathrm{PD}$ in many aspects, the commonalities and differences between $\mathrm{AD}$ and $\mathrm{PD}$ need to be clarified, especially from the viewpoints of clinical manifestation, proteinopathy, vasculopathy, and neurocircuitopathy. To this end, it is necessary to construct a cohort containing both $\mathrm{AD}$ spectrum and $\mathrm{PD}$ spectrum. Related approach has been recently proposed for nation-wide cohort studies including AD and other dementia in Canada and
United Kingdom (Chertkow et al., 2019; Morton et al., 2019; Koychev et al., 2020).

\section{Clinical Viewpoints}

Now, it is recognized that patients in the PD spectrum may show AD-like symptoms, and those in the AD spectrum could also exhibit PD-like symptoms, including anosmia and movement disorders. Anosmia is present in both $\mathrm{AD}$ and PD. Patients with $\mathrm{AD}$ were reported to perform worse than patients with $\mathrm{PD}$ in an odor recognition task (Lehrner et al., 1997). Anosmia in AD is common in cases with Lewy body accumulation in the postmortem brain (Olichney et al., 2005). However, it is not clear how $\alpha$-syn, which constitutes Lewy bodies, is involved in olfaction problems in $\mathrm{AD}$, in contrast to $\mathrm{PD}$, in which neuronal loss occurs in the locus coeruleus, the raphe nuclei, and the nucleus basalis of Meynart (Doty, 2012).

In contrast to the common clinical conception, patients with $\mathrm{PD}$ may present with $\mathrm{AD}$-like memory-dominant cognitive decline (Das et al., 2019). Conversely, some patients with AD may display parkinsonism (Sasaki, 2018). In a longitudinal study of $\mathrm{AD}$ with a mean follow-up of 3.6 years, $12.3 \%$ of patients had clinically apparent parkinsonism at the initial visit, and $22.6 \%$ at the final visit (Portet et al., 2009). Interestingly, patients with $\mathrm{AD}$ complicated with mild parkinsonism exhibit decreased DAT in the caudate nucleus, the pattern of which is closer to DLB than PD (Chung et al., 2019). To our knowledge, no study has directly examined prodromal $\mathrm{PD}$ pathology in $\mathrm{AD}$ with motor symptoms using CSF- $\alpha$-syn or $\alpha$-syn-PET. BPSD with hallucinations, suggestive of monoamine system dysfunction, a hallmark of PD pathology, is also present in AD.

Similarities in clinical manifestations are clearly seen between $\mathrm{AD}$ and PD. Anosmia may point to the common pathophysiology underlying the two. However, since few, if any, large-scale studies used a common clinical scale to compare $\mathrm{AD}$ and $\mathrm{PD}$, it is unclear exactly how similar or different are these common symptoms in the two disorders.

\section{Proteinopathy Viewpoints}

Mounting evidence indicates $\alpha$-syn pathology in the $\mathrm{AD}$ spectrum and $A \beta /$ tau pathology in the $\mathrm{PD}$ spectrum. In animal experiments, many forms of interactions between $\mathrm{AD}$ related proteins and $\mathrm{PD}$-related proteins are reported, and such molecular interactions may explain the mixed $\mathrm{AD}$ and $\mathrm{PD}$ pathology common in humans. It has been suggested that $A \beta$ directly affects the toxicity of $\alpha$-syn. A $\beta$-rich AD-transgenic mice, including PSEN1/2 and APP mutation, show rapid and widespread aggregation of $\alpha$-syn (Bassil et al., 2020). This finding suggests that $A \beta$ plaques may promote seeding and spreading of $\alpha$-syn. Tau and $\alpha$-syn directly interact with each other to promote co-assembly (Bassil et al., 2021). Thus, each abnormal protein promotes the formation of other abnormal proteins.

Most postmortem brains in patients with PDD are complicated by varying degrees of $\mathrm{AD}$ pathology (Dickson et al., 2017). Thus, it is widely accepted that a certain degree of PD cognitive impairment may be associated with AD pathology. In $\mathrm{AD}$, however, approximately $33 \%$ of the patients exhibit 
significant Lewy body pathology alongside $A \beta$ (Deture and Dickson, 2019), especially the presence of Lewy pathology in the olfactory bulb and the amygdala in patients with AD (SerranoPozo et al., 2011; Deture and Dickson, 2019). Also, patients in the PD spectrum show accompanying AD pathology (Kosaka and Manabe, 2010). A multicenter-cohort study of DLB examined $\mathrm{A} \beta$ and $\mathrm{p}$-tau with CSF and PET. Among the patients, $32 \%$ were $\mathrm{A} \beta$ positive, $13 \%$ were $\mathrm{p}$-tau positive, and $15 \%$ were positive for both $A \beta$ and p-tau (Ferreira et al., 2020). A $\beta$ and p-tau were found to be independent risk factors for cognitive decline in DLB. Interestingly, in the same study, p-tau was associated with a lower likelihood of parkinsonism and RBD in DLB.

While amyloid pathology in PDD/DLB is common, the complications of amyloid pathology in non-demented $\mathrm{PD}$ remain unclear. In a study using amyloid-PET, the prevalence rate of $A \beta$ was rather low in non-demented PD patients compared with the healthy population (Mashima et al., 2017). It is possible that the involvement of $A \beta$ pathology may be different in non-demented $\mathrm{PD}$ and PDD/DLB, but further studies are needed.

Because interactions of abnormal proteins in advanced stages of $\mathrm{AD} / \mathrm{PD}$-related dementia may occur, it is important to examine overlapping or interacting proteinopathies even in the preclinical and prodromal stages. In aMCI, which is considered a prodromal stage of $\mathrm{AD}$, patients show cognitive decline that correlates with increased CSF $\alpha$-syn levels (Twohig and Nielsen, 2019). Although few studies have evaluated protein interactions in prodromal $\mathrm{PD}$, the coexistence of $\mathrm{A} \beta$ and tau pathology may promote the progression of prodromal PD to DLB (Berg et al., 2021). Protein interactions in prodromal AD and PD remain unclear, and this requires research attention. Considering that the therapeutic target of each disease is shifting to the early stage, a more thorough understanding of the disease, including protein interactions in the preclinical/prodromal stage, is urgently needed.

\section{Vasculopathy Viewpoints}

Cerebrovascular lesions cause cognitive or motor impairment. However, the significance of vascular lesions including white matter hyperintensities (WMHs) is often underestimated in the pathogenesis of dementia in comparison with, e.g., the proteinopathy viewpoint (Prins and Scheltens, 2015). In the $\mathrm{AD}$ spectrum, multiple studies indicated the presence of vascular lesions as an important background pathology (Prins and Scheltens, 2015; Saito et al., 2015; Muddapu et al., 2020). Decreased amyloid clearance has been proposed for the involvement of WMHs in AD pathogenesis (Saito et al., 2015). WMHs are also considered to underlie dementia in PD (Bohnen and Albin, 2011; Liu et al., 2021).

\section{Neurocircuitopathy Viewpoints}

In $\mathrm{AD}$, many abnormalities in connectivity centering on the hippocampus and $\mathrm{DMN}$, related to $\mathrm{A} \beta$ pathology, have been reported (Takamura and Hanakawa, 2017). In PD, abnormalities in the motor networks, including the basal ganglia and SMN, have been consistently reported. Importantly, DMN abnormalities have been observed in both the $\mathrm{AD}$ and $\mathrm{PD}$ spectra with cognitive impairment. $\mathrm{AD}$ features abnormalities mainly in the precuneus and PCC within the DMN (Ibrahim et al., 2021) whereas DLB has more widespread network abnormalities involving the DMN and the occipital lobe (Wolters et al., 2019).

It seems important to investigate the relationship between proteinopathic abnormalities and neuropsychological indices in the $\mathrm{AD}$ and $\mathrm{PD}$ spectra, and their relationship with the neurocircuitopahty viewpoint, including the DMN abnormality. Existing MRI cohort studies do not allow us to perform such an analysis because they recruit $\mathrm{AD}$ and $\mathrm{PD}$ cohorts independently with different evaluation metrics. Therefore, it remains unknown how $A \beta$, tau and $\alpha$-syn are involved in the differences in DMN abnormalities between $\mathrm{AD}$ and PD. By performing network analysis using biomarkers of both $\mathrm{AD}$ and $\mathrm{PD}$, it may be possible to assess the degree to which each $\mathrm{AD} / \mathrm{PD}$ pathology contributes to network changes. In particular, little is known about the relationship between PD network abnormalities and proteinopathy.

\section{Summary}

Although the presence of substantial overlaps has been demonstrated, AD and PD cohorts have been recruited and evaluated separately. In particular, there is a marked discrepancy between the evaluation metrics for cognitive and neuropsychiatric functions, which limits the utility of existing cohorts for comparing $\mathrm{AD}$ and $\mathrm{PD}$. Therefore, we recommend that a new cohort should be designed to resolve this problem. Each $\mathrm{AD} / \mathrm{PD}$ spectrum should be evaluated throughout the preclinical, prodromal, early, and advanced stages.

Accumulating evidence indicates that the comorbidity of $\mathrm{AD}$ and PD pathology is common in elderly people. Many questions remain unanswered. For example, it is not yet known if the comorbidity is simply coincidental to the aging process per se or if it is caused by the interactions of the key common molecules in $\mathrm{AD}$ and PD. It is not clear when and how the mixed $\mathrm{AD}$ and $\mathrm{PD}$ pathology (i.e., co-pathology) emerges and progresses. Furthermore, it is unclear how the co-pathology affects clinical symptoms, brain structure, and circuit pathology.

To answer these questions, we should first consider merging data from existing cohorts targeting a single disease spectrum for efficiency. There are renown MRI cohorts including ADNI and PPMI (Petersen et al., 2010; Marek et al., 2011; Weiner et al., 2017; Veitch et al., 2019), which have evaluated the AD and PD spectrum separately in depth. For biomarker/genetic studies, it may be worthwhile evaluating a common set of proteins or risk genes from originally distinct cohort. However, it is known that technical differences such as a way to collect, store and measure samples may limit the reliability of the results. For imaging studies, it is still difficult to perform accurate statistical analysis of MRI data obtained from different MR scanners and protocols (Duchesne et al., 2019). Although image analysis methods to remove the scanner difference have been proposed, such methods will remove the difference across the disease spectra when $\mathrm{AD}$ is heavily sampled in some sites and PD is heavily sampled in the others. Also, since each cohort tend to focus on spectral-specific clinical and neuropsychological indices, it is difficult to compare network indices correlated with a common set of neuropsychological indices. Recently, some 


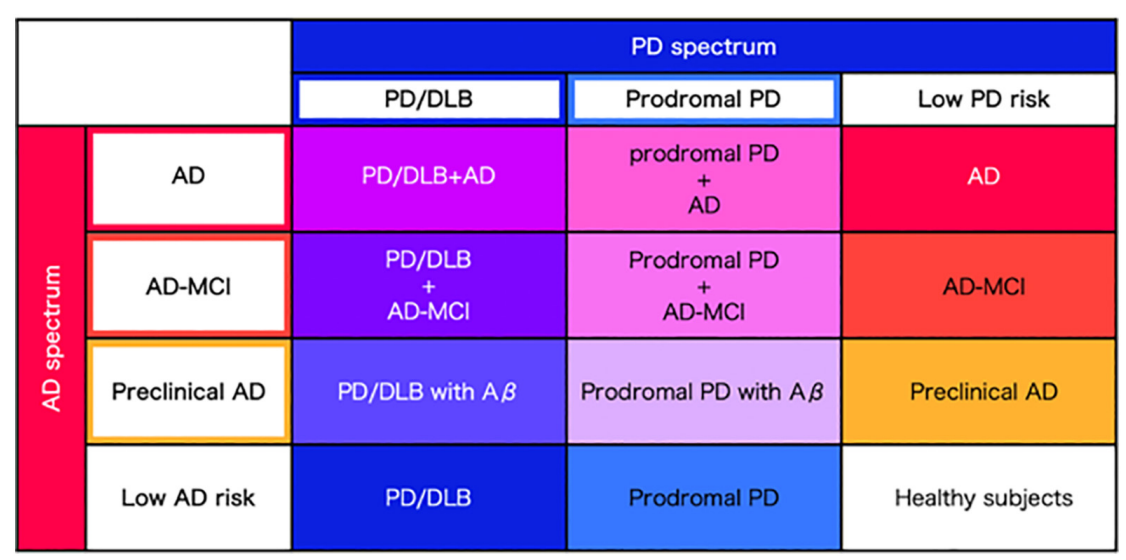

FIGURE 2 | Precise classification of AD and PD spectrum. Regarding AD and PD as spectra, precise disease classification will be performed based on the severity of abnormal protein accumulation and clinical data, derived from each AD and PD spectrum.

PD cohorts employed amyloid and tau PET. It is intriguing to compare spatial distribution of pathological protein across spectra; however, it is still difficult to associate the findings with neuropsychiatric indices with different batteries.

Considering the homology of $\mathrm{AD}$ and $\mathrm{PD}$ spectra in terms of abnormal proteins, vascular factors, motor sand cognitive symptoms, it is most reasonable to perform the same elaborate evaluation in a single cohort employing the same evaluation measures across the spectra. Here we propose to establish a newly designed cohort combining both the AD and PD spectra (Figure 2). Then, symptoms, biomarkers, brain structure and circuit pathology should be evaluated. The unified AD and PD cohort is expected to overcome the limitation of the existing $\mathrm{AD}$ cohort and PD cohort combined.

To investigate the similarities and differences between $\mathrm{AD}$ and $\mathrm{PD}$, it is important to design a cohort study with a few key characteristics. First, it is necessary to apply the same behavioral, cognitive, and neuropsychiatric scales to $\mathrm{AD}$ and PD. Behaviorally, because parkinsonism is sometimes seen in $\mathrm{AD}$, it may be needed to evaluate motor functions of both $\mathrm{AD}$ and PD with MDS-UPDRS. CDR and ADAS, which are used for $\mathrm{AD}$, and $\mathrm{FAB}$ and MoCA, which are used for early $\mathrm{PD}$, may need to be jointly used. It would be interesting to compare the results between PD-MCI in AD-MCI with tests for the five cognitive domains. Unified questionnaire must be used for assessment of behavioral and psychiatric symptoms such as anxiety, depression, and sleep problems, which are common to both AD and PD. The same olfactory test should be applied to $\mathrm{AD}$ and $\mathrm{PD}$ to test anosmia.

Next, $A \beta / p$-tau and $\alpha$-syn should be evaluated for both $A D$ and PD. To date, $A \beta$ and p-tau have been mostly measured for $\mathrm{AD}$ only, and $\alpha$-syn has been measured for PD cohorts only. The same assay methods of these proteins should be applied to blood and spinal fluid obtained from $\mathrm{AD}$ and $\mathrm{PD}$. In postmortem brain research, NFTs appear in the locus coeruleus and entorhinal cortex first, and then spread to the limbic system and neocortex as dementia progresses (Braak and Braak, 1991). To evaluate the spatial distribution of abnormal protein accumulations over time, longitudinal PET imaging is important.
Finally, network and structural abnormalities of the brain should be compared in detail, preferably using the HCPstyle MRI protocol (Glasser et al., 2016; Koike et al., 2021). This modern MRI technology should be combined with the standardized assessment of clinical scales and proteinopathies with fluid biomarkers and SPECT/PET. The effects of A $\beta$, tau and $\alpha$-syn accumulation on network connectivity and their association with symptoms should be examined.

Here are cases where the unified $\mathrm{AD}$ and $\mathrm{PD}$ cohort may provide new knowledge. Clinically, aMCI is often presumed to have AD pathology (Petersen et al., 1999, 2001). The unified AD and PD cohort will provide data to suggest how common is aMCI without evidence for AD pathology but, for example, decreased DAT indicative of the PD spectrum (presumably prodromal DLB). Then, markers of the circuit pathology of such non-AD MCI may be compared with those of PD-MCI "neuroimaged" in the cohort to examine if the markers of neurocircuitopathy could serve as early markers differentiating AD-MCI and non$\mathrm{AD}$ MCI. In the unified $\mathrm{AD}$ and $\mathrm{PD}$ cohort, vascular burden as a common background pathology to $\mathrm{AD}$ and $\mathrm{PD}$ can be evaluated from multiple perspectives, such as interactions of WMH burden with the proteinopathy, symptoms or circuit pathology. We can then ask how WMH burden similarly or differentially modulates manifestation of the $\mathrm{AD}$ spectrum and PD spectrum. The unified AD and PD cohort may also clarify the specific roles of the DMN in cognitive decline in the $\mathrm{AD}$ spectrum and $\mathrm{PD}$ spectrum since DMN is implicated for both $\mathrm{AD}$ and PDD.

\section{CONCLUSION}

Indispensable knowledge has been garnered from previously established AD cohorts and LBD cohorts. Nevertheless, evaluating abnormalities within each disease category only, without knowing the similarities or differences between the two, cannot provide a clear understanding of their pathophysiologies, from protein interactions and disease-spectrum crossovers. Constructing a cohort with multifaceted evaluations for both 
$\mathrm{AD}$ and $\mathrm{LBD}$ is not an easy task. However, longitudinal cohort studies, which meet the requirements proposed above, should provide novel insight into the pathophysiologies of $\mathrm{AD}$ and LBD. This knowledge will in turn provide much-needed data for guiding the development of disease-modifying therapies targeting the pathological proteins in $\mathrm{AD}$ and $\mathrm{LBD}$.

\section{AUTHOR CONTRIBUTIONS}

NW drafted the manuscript. NW and TH wrote the manuscript. Both authors contributed to the article and approved the submitted version.

\section{REFERENCES}

Abe, Y., Kachi, T., Kato, T., Arahata, Y., Yamada, T., Washimi, Y., et al. (2003). Occipital hypoperfusion in Parkinson's disease without dementia: Correlation to impaired cortical visual processing. J. Neurol. Neurosurg. Psychiatry 74, 419-422. doi: 10.1136/jnnp.74.4.419

Adriaanse, S. M., Binnewijzend, M. A. A., Ossenkoppele, R., Tijms, B. M., Van Der Flier, W. M., Koene, T., et al. (2014). Widespread disruption of functional brain organization in early-onset Alzheimer's disease. PLoS One 9:102995. doi: 10.1371/journal.pone.0102995

Agosta, F., Caso, F., Stankovic, I., Inuggi, A., Petrovic, I., Svetel, M., et al. (2014). Cortico-striatal-thalamic network functional connectivity in hemiparkinsonism. Neurobiol. Aging 35, 2592-2602. doi: 10.1016/j. neurobiolaging.2014.05.032

Ahmadi, S. A., Bötzel, K., Levin, J., Maiostre, J., Klein, T., Wein, W., et al. (2020). Analyzing the co-localization of substantia nigra hyper-echogenicities and iron accumulation in Parkinson's disease: A multi-modal atlas study with transcranial ultrasound and MRI. NeuroImage Clin. 26, 102185. doi: 10.1016/j. nicl.2020.102185

Albert, M. S., DeKosky, S. T., Dickson, D., Dubois, B., Feldman, H. H., Fox, N. C., et al. (2011). The diagnosis of mild cognitive impairment due to Alzheimer's disease: recommendations from the National Institute on AgingAlzheimer's Association workgroups on diagnostic guidelines for Alzheimer's disease. Alzheimers. Dement. 7, 270-279. doi: 10.1016/j.jalz.2011.03. 008

Amboni, M., Tessitore, A., Esposito, F., Santangelo, G., Picillo, M., Vitale, C., et al. (2015). Resting-state functional connectivity associated with mild cognitive impairment in Parkinson's disease. J. Neurol. 262, 425-434. doi: 10.1007/ s00415-014-7591-5

Angelova, D. M., and Brown, D. R. (2019). Microglia and the aging brain: are senescent microglia the key to neurodegeneration? J. Neurochem. 151, 676-688. doi: $10.1111 /$ jnc. 14860

Attems, J., Walker, L., and Jellinger, K. A. (2014). Olfactory bulb involvement in neurodegenerative diseases. Acta Neuropathol. 127, 459-475. doi: 10.1007/ s00401-014-1261-7

Ba, F., and Martin, W. R. W. (2015). Dopamine transporter imaging as a diagnostic tool for parkinsonism and related disorders in clinical practice. Park. Relat. Disord. 21, 87-94. doi: 10.1016/j.parkreldis.2014.11.007

Baggio, H.-C., Segura, B., Sala-Llonch, R., Marti, M.-J., Valldeoriola, F., Compta, Y., et al. (2015). Cognitive impairment and resting-state network connectivity in Parkinson's disease. Hum. Brain Mapp. 36, 199-212. doi: 10.1002/hbm.22 622

Bai, F., Xie, C., Watson, D. R., Shi, Y., Yuan, Y., Wang, Y., et al. (2011). Aberrant hippocampal subregion networks associated with the classifications of aMCI subjects: A longitudinal Resting-State study. PLoS One 6:29288. doi: 10.1371/ journal.pone. 0029288

Baiano, C., Barone, P., Trojano, L., and Santangelo, G. (2020). Prevalence and clinical aspects of mild cognitive impairment in Parkinson's disease: A metaanalysis. Mov. Disord. 35, 45-54. doi: 10.1002/mds.27902

\section{FUNDING}

This article was in part supported by the Japan Agency for Medical Research and Development (AMED, https://www.amed.go.jp/en/index.html) (21dm0307003h0004 and 21dm0307004h0004), and the Japan Society for the Promotion of Science (JSPS, www.jsps.go.jp) KAKENHI (19H05726).

\section{ACKNOWLEDGMENTS}

We thank Barry Patel, from Edanz (https://jp.edanz.com/ac), for editing a draft of this manuscript.

Barthélemy, N. R., Horie, K., Sato, C., and Bateman, R. J. (2020). Blood plasma phosphorylated-tau isoforms track CNS change in Alzheimer's disease. J. Exp. Med. 217, 1-12. doi: 10.1084/JEM.20200861

Bassil, F., Brown, H. J., Pattabhiraman, S., Iwasyk, J. E., Maghames, C. M., Meymand, E. S., et al. (2020). Amyloid-Beta (A $\beta$ ) Plaques Promote Seeding and Spreading of Alpha-Synuclein and Tau in a Mouse Model of Lewy Body Disorders with A $\beta$ Pathology. Neuron 105, 260.e-275.e. doi: 10.1016/j.neuron. 2019.10.010

Bassil, F., Meymand, E. S., Brown, H. J., Xu, H., Cox, T. O., Pattabhiraman, S., et al. (2021). $\alpha$-Synuclein modulates tau spreading in mouse brains. J. Exp. Med. 218:20192193. doi: 10.1084/jem.20192193

Bateman, R. J., Xiong, C., Benzinger, T. L. S., Fagan, A. M., Goate, A., Fox, N. C., et al. (2012). Clinical and Biomarker Changes in Dominantly Inherited Alzheimer's Disease. N. Engl. J. Med. 367, 795-804. doi: 10.1056/ nejmoa1202753

Baudrexel, S., Witte, T., Seifried, C., von Wegner, F., Beissner, F., Klein, J. C., et al. (2011). Resting state fMRI reveals increased subthalamic nucleus-motor cortex connectivity in Parkinson's disease. Neuroimage 55, 1728-1738. doi: 10.1016/j. neuroimage.2011.01.017

Beck, A. T., Ward, C. H., Mendelson, M., Mock, J., and Erbaugh, J. (1961). An inventory for measuring depression. Arch. Gen. Psychiatry 4, 561-571. doi: 10.1001/archpsyc.1961.01710120031004

Bell, P. T., Gilat, M., O’Callaghan, C., Copland, D. A., Frank, M. J., Lewis, S. J. G., et al. (2015). Dopaminergic basis for impairments in functional connectivity across subdivisions of the striatum in Parkinson's disease. Hum. Brain Mapp. 36, 1278-1291. doi: 10.1002/hbm.22701

Berg, D., Borghammer, P., Fereshtehnejad, S. M., Heinzel, S., Horsager, J., Schaeffer, E., et al. (2021). Prodromal Parkinson disease subtypes - key to understanding heterogeneity. Nat. Rev. Neurol. 17, 349-361. doi: 10.1038/s41582-02100486-9

Blauwendraat, C., Nalls, M. A., and Singleton, A. B. (2020). The genetic architecture of Parkinson's disease. Lancet Neurol. 19, 170-178. doi: 10.1016/S1474-4422(19) 30287-X

Blennow, K., and Hampel, H. (2003). CSF markers for incipient Alzheimer's disease. Lancet. Neurol. 2, 605-613. doi: 10.1016/s1474-4422(03)00530-1

Bloudek, L. M., Spackman, D. E., Blankenburg, M., and Sullivan, S. D. (2011). Review and meta-analysis of biomarkers and diagnostic imaging in Alzheimer's disease. J. Alzheimers. Dis. 26, 627-645. doi: 10.3233/JAD-2011-110458

Bohnen, N. I., and Albin, R. L. (2011). White matter lesions in Parkinson disease. Nat. Rev. Neurol. 7, 229-236. doi: 10.1038/nrneurol.2011.21

Bonanni, L., Thomas, A., and Onofrj, M. (2006). Diagnosis and management of dementia with Lewy bodies: Third report of the DLB Consortium. Neurology 66:1455. doi: 10.1212/01.wnl.0000224698.67660.45

Borroni, B., Premi, E., Formenti, A., Turrone, R., Alberici, A., Cottini, E., et al. (2015). Structural and functional imaging study in dementia with Lewy bodies and Parkinson's disease dementia. Parkinsonism Relat. Disord. 21, 1049-1055. doi: 10.1016/j.parkreldis.2015.06.013

Boublay, N., Bouet, R., Dorey, J.-M., Padovan, C., Makaroff, Z., Fédérico, D., et al. (2020). Brain Volume Predicts Behavioral and Psychological Symptoms 
in Alzheimer's Disease. J. Alzheimers. Dis. 73, 1343-1353. doi: 10.3233/JAD190612

Braak, H., and Braak, E. (1991). Neuropathological stageing of Alzheimer-related changes. Acta Neuropathol. 82, 239-259. doi: 10.1007/BF00308809

Brigo, F., Matinella, A., Erro, R., and Tinazzi, M. (2014). [ ${ }^{123}$ I]FP-CIT SPECT (DaTSCAN) may be a useful tool to differentiate between Parkinson's disease and vascular or drug-induced parkinsonisms: a meta-analysis. Eur. J. Neurol. 21, 1369-e90. doi: 10.1111/ene.12444

Bucci, M., Chiotis, K., and Nordberg, A. (2021). Alzheimer's disease profiled by fluid and imaging markers: tau PET best predicts cognitive decline. Mol. Psychiatry 2021:2. doi: 10.1038/s41380-021-01263-2

Buckner, R. L., Snyder, A. Z., Shannon, B. J., LaRossa, G., Sachs, R., Fotenos, A. F., et al. (2005). Molecular, structural, and functional characterization of Alzheimer's disease: Evidence for a relationship between default activity, amyloid, and memory. J. Neurosci. 25, 7709-7717. doi: 10.1523/JNEUROSCI. 2177-05.2005

Burton, E. J., McKeith, I. G., Burn, D. J., Williams, E. D., and O’Brien, J. T. (2004). Cerebral atrophy in Parkinson's disease with and without dementia: A comparison with Alzheimer's disease, dementia with Lewy bodies and controls. Brain 127, 791-800. doi: 10.1093/brain/awh088

Caillava-Santos, F., Margis, R., and de Mello Rieder, C. R. (2015). Wearing-off in Parkinson's disease: Neuropsychological differences between on and off periods. Neuropsychiatr. Dis. Treat. 11, 1175-1180. doi: 10.2147/NDT.S77060

Camicioli, R., Moore, M. M., Kinney, A., Corbridge, E., Glassberg, K., and Kaye, J. A. (2003). Parkinson's disease is associated with hippocampal atrophy. Mov. Disord. 18, 784-790. doi: 10.1002/mds.10444

Campbell, M. C., Koller, J. M., Snyder, A. Z., Buddhala, C., Kotzbauer, P. T., and Perlmutter, J. S. (2015). CSF proteins and resting-state functional connectivity in Parkinson disease. Neurology 84, 2413-2421. doi: 10.1212/WNL. 0000000000001681

Canu, E., Agosta, F., Sarasso, E., Volontè, M. A., Basaia, S., Stojkovic, T., et al. (2015). Brain structural and functional connectivity in Parkinson's disease with freezing of gait. Hum. Brain Mapp. 36, 5064-5078. doi: 10.1002/hbm.22994

Cavanna, A. E., and Trimble, M. R. (2006). The precuneus: A review of its functional anatomy and behavioural correlates. Brain 129, 564-583. doi: 10. 1093/brain/awl004

Celone, K. A., Calhoun, V. D., Dickerson, B. C., Atri, A., Chua, E. F., Miller, S. L., et al. (2006). Alterations in memory networks in mild cognitive impairment and Alzheimer's disease: An independent component analysis. J. Neurosci. 26, 10222-10231. doi: 10.1523/JNEUROSCI.2250-06.2006

Chang, C. W., Yang, S. Y., Yang, C. C., Chang, C. W., and Wu, Y. R. (2020). Plasma and Serum Alpha-Synuclein as a Biomarker of Diagnosis in Patients With Parkinson's Disease. Front. Neurol. 10:1-7. doi: 10.3389/fneur.2019. 01388

Chang, Y. L., Bondi, M. W., McEvoy, L. K., Fennema-Notestine, C., Salmon, D. P., Galasko, D., et al. (2011). Global clinical dementia rating of 0.5 in MCI masks variability related to level of function. Neurology 76, 652-659. doi: 10.1212/ WNL.0b013e31820ce6a5

Chen, B., Fan, G. G., Liu, H., and Wang, S. (2015). Changes in anatomical and functional connectivity of Parkinson's disease patients according to cognitive status. Eur. J. Radiol. 84, 1318-1324. doi: 10.1016/j.ejrad.2015.04.014

Chen, H. M., Wang, Z. J., Fang, J. P., Gao, L. Y., Ma, L. Y., Wu, T., et al. (2015). Different Patterns of Spontaneous Brain Activity between Tremor-Dominant and Postural Instability/Gait Difficulty Subtypes of Parkinson's Disease: A Resting-State fMRI Study. CNS Neurosci. Ther. 21, 855-866. doi: 10.1111/cns. 12464

Chen, Q., Chen, Y., Zhang, Y., Wang, F., Yu, H., Zhang, C., et al. (2019). Iron deposition in Parkinson's disease by quantitative susceptibility mapping. BMC Neurosci. 20, 1-8. doi: 10.1186/s12868-019-0505-9

Chen, X., Lu, B., and Yan, C.-G. (2018). Reproducibility of R-fMRI metrics on the impact of different strategies for multiple comparison correction and sample sizes. Hum. Brain Mapp. 39, 300-318. doi: 10.1002/hbm.23843

Cheng, Q., Huang, J., Liang, J., Ma, M., Zhao, Q., Lei, X., et al. (2020). Evaluation of abnormal iron distribution in specific regions in the brains of patients with Parkinson's disease using quantitative susceptibility mapping and R2* mapping. Exp. Ther. Med. 2020, 3778-3786. doi: 10.3892/etm.2020.8645

Chertkow, H., Borrie, M., Whitehead, V., Black, S. E., Feldman, H. H., Gauthier, S., et al. (2019). The comprehensive assessment of neurodegeneration and dementia: Canadian cohort study. Can. J. Neurol. Sci. 46, 499-511. doi: 10.1017/ cjn.2019.27

Chételat, G., Arbizu, J., Barthel, H., Garibotto, V., Law, I., Morbelli, S., et al. (2020). Amyloid-PET and 18F-FDG-PET in the diagnostic investigation of Alzheimer's disease and other dementias. Lancet Neurol. 19, 951-962. doi: 10.1016/S14744422(20)30314-8

Chhatwal, J. P., and Sperling, R. A. (2012). Functional MRI of mnemonic networks across the spectrum of normal aging, mild cognitive impairment, and Alzheimer's disease. J. Alzheimers. Dis. 31(Suppl. 3), S155-S167. doi: 10.3233/ JAD-2012-120730

Chung, S. J., Lee, Y. H., Yoo, H. S., Sohn, Y. H., Ye, B. S., Cha, J., et al. (2019). Distinct FP-CIT PET patterns of Alzheimer's disease with parkinsonism and dementia with Lewy bodies. Eur. J. Nucl. Med. Mol. Imaging 46, 1652-1660. doi: 10.1007/s00259-019-04315-6

Clment, F., and Belleville, S. (2010). Compensation and disease severity on the memory-related activations in mild cognitive impairment. Biol. Psychiatry 68, 894-902. doi: 10.1016/j.biopsych.2010.02.004

Colin, M., Dujardin, S., Schraen-Maschke, S., Meno-Tetang, G., Duyckaerts, C., Courade, J. P., et al. (2020). From the prion-like propagation hypothesis to therapeutic strategies of anti-tau immunotherapy. Acta Neuropathol. 139, 3-25. doi: 10.1007/s00401-019-02087-9

Córdova-Palomera, A., Kaufmann, T., Persson, K., Alnæs, D., Doan, N. T., Moberget, T., et al. (2017). Disrupted global metastability and static and dynamic brain connectivity across individuals in the Alzheimer's disease continuum. Sci. Rep. 7, 1-14. doi: 10.1038/srep40268

Crary, J. F., Trojanowski, J. Q., Schneider, J. A., Abisambra, J. F., Abner, E. L., Alafuzoff, I., et al. (2014). Primary age-related tauopathy (PART): a common pathology associated with human aging. Acta Neuropathol. 128, 755-766. doi: 10.1007/s00401-014-1349-0

Daerr, S., Brendel, M., Zach, C., Mille, E., Schilling, D., Zacherl, M. J., et al. (2017). Evaluation of early-phase [18F]-florbetaben PET acquisition in clinical routine cases. NeuroImage Clin. 14, 77-86. doi: 10.1016/j.nicl.2016. 10.005

Dagher, A., and Zeighami, Y. (2018). Testing the Protein Propagation Hypothesis of Parkinson Disease. J. Exp. Neurosci. 12, 0-3. doi: 10.1177/117906951878 6715

Das, T., Hwang, J. J., and Poston, K. L. (2019). Episodic recognition memory and the hippocampus in Parkinson's disease: A review. Cortex 113, 191-209. doi: 10.1016/j.cortex.2018.11.021

Davis, D., Creavin, S., Yip, J., Noel-Storr, A., and Cullum, S. (2015). Montreal Cognitive Assessment for the diagnosis of Alzheimer's disease and other dementias. Cochrane Database Syst. Rev. Montr. 2015:10775. doi: 10.1002/ 14651858.CD010775.pub2.www.cochranelibrary.com

De Meyer, G., Shapiro, F., Vanderstichele, H., Vanmechelen, E., Engelborghs, S., Paul, et al. (2010). Diagnosis-Independent Alzheimer Disease Biomarker Signature in Cognitively Normal Elderly People. Available online at: www.loni.ucla.edu [Accessed June 19, 2021]

de Vos, F., Koini, M., Schouten, T. M., Seiler, S., van der Grond, J., Lechner, A., et al. (2018). A comprehensive analysis of resting state fMRI measures to classify individual patients with Alzheimer's disease. Neuroimage 167, 62-72. doi: 10.1016/j.neuroimage.2017.11.025

Demirtaş, M., Falcon, C., Tucholka, A., Gispert, J. D., Molinuevo, J. L., and Deco, G. (2017). A whole-brain computational modeling approach to explain the alterations in resting-state functional connectivity during progression of Alzheimer's disease. NeuroImage Clin. 16, 343-354. doi: 10.1016/j.nicl.2017. 08.006

Deture, M. A., and Dickson, D. W. (2019). The neuropathological diagnosis of Alzheimer's disease. Mol. Neurodegener. 14, 1-18. doi: 10.1186/s13024-0190333-5

Dichgans, M., and Leys, D. (2017). Vascular Cognitive Impairment. Circ. Res. 120, 573-591. doi: 10.1161/CIRCRESAHA.116.308426

Dickerson, B. C., Salat, D. H., Bates, J. F., Atiya, M., Killiany, R. J., Greve, D. N., et al. (2004). Medial temporal lobe function and structure in mild cognitive impairment. Ann. Neurol. 56, 27-35. doi: 10.1002/ana.20163

Dickerson, B. C., Salat, D. H., Greve, D. N., Chua, E. F., Rand-Giovannetti, E., Rentz, D. M., et al. (2005). Increased hippocampal activation in mild cognitive impairment compared to normal aging and AD. Neurology 65, 404-411. doi: 10.1212/01.wnl.0000171450.97464.49 
Dickson, D. W., Halliday, G., Aarsland, D., Attems, J., Ballard, C. G., Bayston, A., et al. (2017). Diagnosis and management of dementia with Lewy bodies: Fourth consensus report of the DLB Consortium. Neurology 89, 1-14.

Dirkx, M. F., den Ouden, H., Aarts, E., Timmer, M., Bloem, B. R., Toni, I., et al. (2016). The cerebral network of parkinson's tremor: An effective connectivity fMRI study. J. Neurosci. 36, 5362-5372. doi: 10.1523/JNEUROSCI.3634-15. 2016

Doty, R. L. (2012). Olfactory dysfunction in Parkinson disease. Nat. Rev. Neurol. 8, 329-339. doi: 10.1038/nrneurol.2012.80

Dubois, B., Feldman, H. H., Jacova, C., Hampel, H., Molinuevo, J. L., Blennow, K., et al. (2014). Advancing research diagnostic criteria for Alzheimer's disease: the IWG-2 criteria. Lancet. Neurol. 13, 614-629. doi: 10.1016/S1474-4422(14) 70090-0

Dubois, B., Slachevsky, A., Litvan, I., and Pillon, B. (2000). The FAB. Neurology 55, 1621-1626.

Duchesne, S., Chouinard, I., Potvin, O., Fonov, V. S., Khademi, A., Bartha, R., et al. (2019). The Canadian Dementia Imaging Protocol: Harmonizing National Cohorts. J. Magn. Reson. Imaging 49, 456-465. doi: 10.1002/jmri.26197

Eramudugolla, R., Mortby, M. E., Sachdev, P., Meslin, C., Kumar, R., and Anstey, K. J. (2017). Evaluation of a research diagnostic algorithm for DSM5 neurocognitive disorders in a population-based cohort of older adults. Alzheimer's Res. Ther. 9, 1-12. doi: 10.1186/s13195-017-0246-x

Esposito, F., Tessitore, A., Giordano, A., De Micco, R., Paccone, A., Conforti, R., et al. (2013). Rhythm-specific modulation of the sensorimotor network in drug-naive patients with Parkinson's disease by levodopa. Brain 136, 710-725. doi: 10.1093/brain/awt007

Fairfoul, G., McGuire, L. I., Pal, S., Ironside, J. W., Neumann, J., Christie, S., et al. (2016). Alpha-synuclein RT-QuIC in the CSF of patients with alpha-synucleinopathies. Ann. Clin. Transl. Neurol. 3, 812-818. doi: 10.1002/ acn 3.338

Ferrari, C. C., and Tarelli, R. (2011). Parkinson's disease and systemic inflammation. Parkinsons. Dis. 2011:436813. doi: 10.4061/2011/436813

Ferreira, D., Przybelski, S. A., Lesnick, T. G., Lemstra, A. W., Londos, E., Blanc, F., et al. (2020). $\beta$-Amyloid and tau biomarkers and clinical phenotype in dementia with Lewy bodies. Neurology 95, e3257-e3268. doi: 10.1212/WNL. 0000000000010943

Filippi, M., Sarasso, E., and Agosta, F. (2019). Resting-state Functional MRI in Parkinsonian Syndromes. Mov. Disord Clin. Pr. 6, 104-117. doi: 10.1002/mdc3. 12730

Flicker, C., Ferris, S. H., and Reisberg, B. (1991). Mild cognitive impairment in the elderly: predictors of dementia. Neurology 41, 1006-1009. doi: 10.1212/wnl.41. 7.1006

Fling, B. W., Cohen, R. G., Mancini, M., Carpenter, S. D., Fair, D. A., Nutt, J. G., et al. (2014). Functional reorganization of the locomotor network in parkinson patients with freezing of gait. PLoS One 9:291. doi: 10.1371/journal. pone.0100291

Galts, C. P. C., Bettio, L. E. B., Jewett, D. C., Yang, C. C., Brocardo, P. S., Rodrigues, A. L. S., et al. (2019). Depression in neurodegenerative diseases: Common mechanisms and current treatment options. Neurosci. Biobehav. Rev. 102, 56-84. doi: 10.1016/j.neubiorev.2019.04.002

Galvin, J. E., Price, J. L., Yan, Z., Morris, J. C., and Sheline, Y. I. (2011). Resting bold fMRI differentiates dementia with Lewy bodies vs Alzheimer disease. Neurology 76, 1797-1803. doi: 10.1212/WNL.0b013e31821ccc83

Ganguly, U., Singh, S., Pal, S., Prasad, S., Agrawal, B. K., Saini, R. V., et al. (2021). Alpha-Synuclein as a Biomarker of Parkinson's Disease: Good, but Not Good Enough. Front. Aging Neurosci. 13, 1-19. doi: 10.3389/fnagi.2021.702639

Gegg, M. E., Burke, D., Heales, S. J. R., Cooper, J. M., Hardy, J., Wood, N. W., et al. (2012). Glucocerebrosidase deficiency in substantia nigra of parkinson disease brains. Ann. Neurol. 72, 455-463. doi: 10.1002/ana.23614

Gibb, W. R., and Lees, A. J. (1988). The relevance of the Lewy body to the pathogenesis of idiopathic Parkinson's disease. J. Neurol. Neurosurg. Psychiatry 51, 745-752. doi: 10.1136/jnnp.51.6.745

Glasser, M. F., Smith, S. M., Marcus, D. S., Andersson, J. L. R., Auerbach, E. J., Behrens, T. E. J., et al. (2016). The Human Connectome Project's neuroimaging approach. Nat. Neurosci. 19, 1175-1187. doi: 10.1038/nn.4361

Goetz, C. G., Tilley, B. C., Shaftman, S. R., Stebbins, G. T., Fahn, S., MartinezMartin, P., et al. (2008). Movement Disorder Society-sponsored revision of the Unified Parkinson's Disease Rating Scale (MDS-UPDRS): scale presentation and clinimetric testing results. Mov. Disord 23, 2129-2170. doi: 10.1002/mds. 22340

Goldman, J. G., Vernaleo, B. A., Camicioli, R., Dahodwala, N., Dobkin, R. D., Ellis, T., et al. (2018). Cognitive impairment in Parkinson's disease: a report from a multidisciplinary symposium on unmet needs and future directions to maintain cognitive health. npj Park. Dis. 4, 1-11. doi: 10.1038/s41531-018-0055-3

Gorges, M., Müller, H.-P., Lulé, D., Pinkhardt, E. H., Ludolph, A. C., and Kassubek, J. (2015). To rise and to fall: functional connectivity in cognitively normal and cognitively impaired patients with Parkinson's disease. Neurobiol. Aging 36, 1727-1735. doi: 10.1016/j.neurobiolaging.2014.12.026

Graff-Radford, J., Murray, M. E., Lowe, V. J., Boeve, B. F., Ferman, T. J., Przybelski, S. A., et al. (2014). Dementia with Lewy bodies: basis of cingulate island sign. Neurology 83, 801-809. doi: 10.1212/WNL.0000000000000734

Greicius, M. D., Krasnow, B., Reiss, A. L., and Menon, V. (2003). Functional connectivity in the resting brain: A network analysis of the default mode hypothesis. Proc. Natl. Acad. Sci. U. S. A. 100, 253-258. doi: 10.1073/pnas. 0135058100

Guan, X., Zeng, Q., Guo, T., Wang, J., Xuan, M., Gu, Q., et al. (2017). Disrupted functional connectivity of basal ganglia across tremor-dominant and akinetic/rigid-dominant Parkinson's disease. Front. Aging Neurosci. 9, 1-11. doi: 10.3389/fnagi.2017.00360

Guerreiro, R., Wojtas, A., Bras, J., Carrasquillo, M., Rogaeva, E., Majounie, E., et al. (2013). TREM2 Variants in Alzheimer's Disease. N. Engl. J. Med. 368, 117-127. doi: 10.1056/nejmoa1211851

Guo, T., Noble, W., and Hanger, D. P. (2017). Roles of tau protein in health and disease. Acta Neuropathol. 133, 665-704. doi: 10.1007/s00401-017-1707-9

Hacker, C. D., Perlmutter, J. S., Criswell, S. R., Ances, B. M., and Snyder, A. Z. (2012). Resting state functional connectivity of the striatum in Parkinson's disease. Brain 135, 3699-3711. doi: 10.1093/brain/aws281

Hall, J. M., Ehgoetz Martens, K. A., Walton, C. C., O'Callaghan, C., Keller, P. E., Lewis, S. J. G., et al. (2016). Diffusion alterations associated with Parkinson's disease symptomatology: A review of the literature. Park. Relat. Disord. 33, 12-26. doi: 10.1016/j.parkreldis.2016.09.026

Hampel, H., Frank, R., Broich, K., Teipel, S. J., Katz, R. G., Hardy, J., et al. (2010). Biomarkers for alzheimer's disease: Academic, industry and regulatory perspectives. Nat. Rev. Drug Discov. 9, 560-574. doi: 10.1038/nrd3115

Hampel, H., and Teipel, S. J. (2004). Total and phosphorylated tau proteins: evaluation as core biomarker candidates in frontotemporal dementia. Dement. Geriatr. Cogn. Disord. 17, 350-354. doi: 10.1159/000077170

Hanagasi, H. A., Tufekcioglu, Z., and Emre, M. (2017). Dementia in Parkinson's disease. J. Neurol. Sci. 374, 26-31. doi: 10.1016/j.jns.2017.01.012

Hauser, P. S., Narayanaswami, V., and Ryan, R. O. (2011). Apolipoprotein E: from lipid transport to neurobiology. Prog. Lipid Res. 50, 62-74. doi: 10.1016/j. plipres.2010.09.001

Heinzel, S., Berg, D., Gasser, T., Chen, H., Yao, C., and Postuma, R. B. (2019). Update of the MDS research criteria for prodromal Parkinson's disease. Mov. Disord. 34, 1464-1470. doi: 10.1002/mds.27802

Helmich, R. C., Derikx, L. C., Bakker, M., Scheeringa, R., Bloem, B. R., and Toni, I. (2010). Spatial remapping of cortico-striatal connectivity in parkinson's disease. Cereb. Cortex 20, 1175-1186. doi: 10.1093/cercor/bhp178

Helmich, R. C., Janssen, M. J. R., Oyen, W. J. G., Bloem, B. R., and Toni, I. (2011). Pallidal dysfunction drives a cerebellothalamic circuit into Parkinson tremor. Ann. Neurol. 69, 269-281. doi: 10.1002/ana.22361

Henderson, M. X., Trojanowski, J. Q., and Lee, V. M. Y. (2019). $\alpha$-Synuclein pathology in Parkinson's disease and related $\alpha$-synucleinopathies. Neurosci. Lett. 709:134316. doi: 10.1016/j.neulet.2019.134316

Herz, D. M., Eickhoff, S. B., Løkkegaard, A., and Siebner, H. R. (2014). Functional neuroimaging of motor control in parkinson's disease: A meta-analysis. Hum. Brain Mapp. 35, 3227-3237. doi: 10.1002/hbm.22397

Hodges, J. R., and Patterson, K. (1997). Semantic memory disorders. Trends Cogn. Sci. 1, 68-72. doi: 10.1016/S1364-6613(97)01022-X

Hohenfeld, C., Werner, C. J., and Reetz, K. (2018). Resting-state connectivity in neurodegenerative disorders: Is there potential for an imaging biomarker? NeuroImage Clin. 18, 849-870. doi: 10.1016/j.nicl.2018.03.013

Honey, C. J., Sporns, O., Cammoun, L., Gigandet, X., Thiran, J. P., Meuli, R., et al. (2009). Predicting human resting-state functional connectivity from structural connectivity. Proc. Natl. Acad. Sci. U. S. A. 106, 2035-2040. doi: 10.1073/pnas. 0811168106 
Hou, Y., Dan, X., Babbar, M., Wei, Y., Hasselbalch, S. G., Croteau, D. L., et al. (2019). Ageing as a risk factor for neurodegenerative disease. Nat. Rev. Neurol. 15, 565-581. doi: 10.1038/s41582-0190244-7

Hou, Y., Yang, J., Luo, C., Ou, R., Zou, Y., Song, W., et al. (2018b). Restingstate network connectivity in cognitively unimpaired drug-naïve patients with rigidity-dominant Parkinson's disease. J. Neurol. Sci. 395, 147-152. doi: 10.1016/ j.jns.2018.10.003

Hou, Y., Ou, R., Yang, J., Song, W., Gong, Q., and Shang, H. (2018a). Patterns of striatal and cerebellar functional connectivity in early-stage drug-naïve patients with Parkinson's disease subtypes. Neuroradiology 60, 1323-1333. doi: 10.1007/ s00234-018-2101-6

Hruska, K. S., LaMarca, M. E., Scott, C. R., and Sidransky, E. (2008). Gaucher disease: Mutation and polymorphism spectrum in the glucocerebrosidase gene (GBA). Hum. Mutat. 29, 567-583. doi: 10.1002/humu.20676

Hu, X., Zhang, J., Jiang, X., Zhou, C., Wei, L., Yin, X., et al. (2015). Decreased interhemispheric functional connectivity in subtypes of Parkinson's disease. J. Neurol. 262, 760-767. doi: 10.1007/s00415-014-7627-x

Hughes, A. J., Daniel, S. E., Kilford, L., and Lees, A. J. (1992). Accuracy of clinical diagnosis of idiopathic Parkinson's disease: A clinico-pathological study of 100 cases. J. Neurol. Neurosurg. Psychiatry 55, 181-184. doi: 10.1136/jnnp.55.3.181

Ibarretxe-Bilbao, N., Ramírez-Ruiz, B., Tolosa, E., Martí, M. J., Valldeoriola, F., Bargalló, N., et al. (2008). Hippocampal head atrophy predominance in Parkinson's disease with hallucinations and with dementia. J. Neurol. 255, 1324-1331. doi: 10.1007/s00415-008-0885-8

Ibrahim, B., Suppiah, S., Ibrahim, N., Mohamad, M., Hassan, H. A., Nasser, N. S., et al. (2021). Diagnostic power of resting-state fMRI for detection of network connectivity in Alzheimer's disease and mild cognitive impairment: A systematic review. Hum. Brain Mapp. 42, 2941-2968. doi: 10.1002/hbm.25369

Irwin, D. J., Lee, V. M. Y., and Trojanowski, J. Q. (2013). Parkinson's disease dementia: Convergence of $\alpha$-synuclein, tau and amyloid- $\beta$ pathologies. Nat. Rev. Neurosci. 14, 626-636. doi: 10.1038/nrn3549

Ishii, M., Hiller, A. J., Pham, L., McGuire, M. J., Iadecola, C., and Wang, G. (2019). Amyloid-Beta Modulates Low-Threshold Activated Voltage-Gated L-Type Calcium Channels of Arcuate Neuropeptide Y Neurons Leading to Calcium Dysregulation and Hypothalamic Dysfunction. J. Neurosci. 39, 88168825. doi: 10.1523/JNEUROSCI.0617-19.2019

Jack, C. R. Jr., Bennett, D. A., Blennow, K., Carrillo, M. C., Dunn, B., Haeberlein, S. B., et al. (2018). NIA-AA Research Framework: Toward a biological definition of Alzheimer's disease. Alzheimers Dement 14, 535-562. doi: 10.1016/j.jalz.2018. 02.018

Jansen, W. J., Ossenkoppele, R., Knol, D. L., Tijms, B. M., Scheltens, P., Verhey, F. R. J., et al. (2015). Prevalence of cerebral amyloid pathology in persons without dementia: A meta-analysis. JAMA - J. Am. Med. Assoc. 313, 1924-1938. doi: 10.1001/jama.2015.4668

Jellinger, K. A., and Korczyn, A. D. (2018). Are dementia with Lewy bodies and Parkinson's disease dementia the same disease? BMC Med. 16:1-16. doi: 10. 1186/s12916-018-1016-8

Jiang, Q., Lee, C. Y. D., Mandrekar, S., Wilkinson, B., Cramer, P., Zelcer, N., et al. (2008). ApoE Promotes the Proteolytic Degradation of A $\beta$. Neuron 58, 681-693. doi: 10.1016/j.neuron.2008.04.010

Jindal, K., and Bansal, A. (2016). APOE\&2 is associated with milder clinical and pathological Alzheimer's disease. Ann. Neurosci. 23:112. doi: 10.1159/ 000443572

Joie, R., La, Visani, A. V., Baker, S. L., Brown, J. A., Bourakova, V., et al. (2020). Prospective longitudinal atrophy in Alzheimer's disease correlates with the intensity and topography of baseline tau-PET. Sci. Transl. Med. 12, 1-13. doi: 10.1126/scitranslmed.aau5732

Jonsson, T., Stefansson, H., Steinberg, S., Jonsdottir, I., Jonsson, P. V., Snaedal, J., et al. (2013). Variant of TREM2 Associated with the Risk of Alzheimer's Disease. N. Engl. J. Med. 368, 107-116. doi: 10.1056/nejmoa1211103

Junqué, C., Ramírez-Ruiz, B., Tolosa, E., Summerfield, C., Martí, M. J., Pastor, P., et al. (2005). Amygdalar and hippocampal MRI volumetric reductions in Parkinson's disease with dementia. Mov. Disord. 20, 540-544. doi: 10.1002/mds. 20371

Kakuda, K., Ikenaka, K., Araki, K., So, M., Aguirre, C., Kajiyama, Y., et al. (2019). Ultrasonication-based rapid amplification of $\alpha$-synuclein aggregates in cerebrospinal fluid. Sci. Rep. 9, 1-10. doi: 10.1038/s41598-019-42399-0
Kamagata, K., Motoi, Y., Abe, O., Shimoji, K., Hori, M., Nakanishi, A., et al. (2012). White matter alteration of the cingulum in Parkinson disease with and without dementia: Evaluation by diffusion tensor tract-specific analysis. Am. J. Neuroradiol. 33, 890-895. doi: 10.3174/ajnr.A2860

Kantarci, K., Lowe, V. J., Boeve, B. F., Senjem, M. L., Tosakulwong, N., Lesnick, T. G., et al. (2017). AV-1451 tau and $\beta$-amyloid positron emission tomography imaging in dementia with Lewy bodies. Ann. Neurol. 81, 58-67. doi: 10.1002/ ana. 24825

Karunanayaka, P. R., Lee, E. Y., Lewis, M. M., Sen, S., Eslinger, P. J., Yang, Q. X., et al. (2016). Default mode network differences between rigidity- and tremorpredominant Parkinson's disease. Cortex 81, 239-250. doi: 10.1016/j.cortex. 2016.04.021

Kim, H. K., Yoo, K., Na, D. L., Seo, S. W., Jeong, J., and Jeong, Y. (2015). Non-monotonic reorganization of brain networks with Alzheimer's disease progression. Front. Aging Neurosci. 7:1-10. doi: 10.3389/fnagi.2015.00111

Koike, S., Tanaka, S. C., Okada, T., Aso, T., Yamashita, A., Yamashita, O., et al. (2021). Brain/MINDS beyond human brain MRI project: A protocol for multi-level harmonization across brain disorders throughout the lifespan. NeuroImage Clin. 2021:102600. doi: 10.1016/j.nicl.2021.102600

Kosaka, K., and Manabe, Y. (2010). The first autopsied case of diffuse Lewy body disease (DLBD): Re-examination by recent immunostaining methods: The 50th Anniversary of Japanese Society of Neuropathology. Neuropathology 30, 458-462. doi: 10.1111/j.1440-1789.2010.01128.x

Koychev, I., Young, S., Holve, H., Ben Yehuda, M., and Gallacher, J. (2020). Dementias Platform UK Clinical Studies and Great Minds Register: Protocol of a targeted brain health studies recontact database. BMJ Open 10, 1-10. doi: 10.1136/bmjopen-2020-040766

Kuebler, L., Buss, S., Leonov, A., Ryazanov, S., Schmidt, F., Maurer, A., et al. (2021). [11C]MODAG-001-towards a PET tracer targeting $\alpha$-synuclein aggregates. Eur. J. Nucl. Med. Mol. Imaging 48, 1759-1772. doi: 10.1007/s00259-02005133-X

Kueper, J. K., Speechley, M., and Montero-Odasso, M. (2018). The Alzheimer's Disease Assessment Scale-Cognitive Subscale (ADAS-Cog): Modifications and Responsiveness in Pre-Dementia Populations. A Narrative Review. J. Alzheimers Dis. 63, 423-444. doi: 10.3233/jad-170991

Laakso, M. P., Partanen, K., Riekkinen, P., Lehtovirta, M., Helkala, E. L., Hallikainen, M., et al. (1996). Hippocampal volumes in Alzheimer's disease, Parkinson's disease with and without dementia, and in vascular dementia: An MRI study. Neurology 46, 678-681. doi: 10.1212/wnl.46.3.678

Langley, J., Huddleston, D. E., Merritt, M., Chen, X., McMurray, R., Silver, M., et al. (2016). Diffusion tensor imaging of the substantia nigra in Parkinson's disease revisited. Hum. Brain Mapp. 37, 2547-2556. doi: 10.1002/hbm.23192

Lawton, M., Baig, F., Toulson, G., Morovat, A., Evetts, S. G., Ben-Shlomo, Y., et al. (2020). Blood biomarkers with Parkinson's disease clusters and prognosis: The oxford discovery cohort. Mov. Disord. 35, 279-287. doi: 10.1002/mds. 27888

Le Heron, C., Apps, M. A. J., and Husain, M. (2018). The anatomy of apathy: A neurocognitive framework for amotivated behaviour. Neuropsychologia 118, 54-67. doi: 10.1016/j.neuropsychologia.2017.07.003

Leech, R., Kamourieh, S., Beckmann, C. F., and Sharp, D. J. (2011). Fractionating the default mode network: Distinct contributions of the ventral and dorsal posterior cingulate cortex to cognitive control. J. Neurosci. 31, 3217-3224. doi: 10.1523/JNEUROSCI.5626-10.2011

Lees, A. J., Hardy, J., and Revesz, T. (2009). Parkinson's disease. Lancet 373, 2055-2066. doi: 10.1016/S0140-6736(09)60492-X

Lehrner, J. P., Brücke, T., Dal-Bianco, P., Gatterer, G., and Kryspin-Exner, I. (1997). Olfactory Functions in Parkinson's Disease and Alzheimer's Disease. Chem. Senses 22, 105-110. doi: 10.1093/chemse/22.1.105

Leuzy, A., Chiotis, K., Lemoine, L., Gillberg, P. G., Almkvist, O., Rodriguez-Vieitez, E., et al. (2019). Tau PET imaging in neurodegenerative tauopathies-still a challenge. Mol. Psychiatry 24, 1112-1134. doi: 10.1038/s41380-018-0342-8

Lewis, M. M., Du, G., Lee, E. Y., Nasralah, Z., Sterling, N. W., Zhang, L., et al. (2016). The pattern of gray matter atrophy in Parkinson's disease differs in cortical and subcortical regions. J. Neurol. 263, 68-75. doi: 10.1007/s00415-0157929-7

Li, Q. X., Mok, S. S., Laughton, K. M., McLean, C. A., Cappai, R., Masters, C. L., et al. (2007). Plasma $\alpha$-synuclein is decreased in subjects with Parkinson's disease. Exp. Neurol. 204, 583-588. doi: 10.1016/j.expneurol.2006.12.006 
Litvan, I., Goldman, J. G., Tröster, A. I., Schmand, B. A., Weintraub, D., Petersen, R. C., et al. (2012). Diagnostic criteria for mild cognitive impairment in Parkinson's disease: Movement Disorder Society Task Force guidelines. Mov. Disord. 27, 349-356. doi: 10.1002/mds.24893

Liu, C. C., Kanekiyo, T., Xu, H., and Bu, G. (2013). Apolipoprotein e and Alzheimer disease: Risk, mechanisms and therapy. Nat. Rev. Neurol. 9, 106-118. doi: 10. 1038/nrneurol.2012.263

Liu, H., Deng, B., Xie, F., Yang, X., Xie, Z., Chen, Y., et al. (2021). The influence of white matter hyperintensity on cognitive impairment in Parkinson's disease. Ann. Clin. Transl. Neurol. 8, 1917-1934. doi: 10.1002/acn3. 51429

Liu, T. T. (2013). Neurovascular factors in resting-state functional MRI. Neuroimage 80, 339-348. doi: 10.1016/j.neuroimage.2013.04.071

Maass, F., Schulz, I., Lingor, P., Mollenhauer, B., and Bähr, M. (2019). Cerebrospinal fluid biomarker for Parkinson's disease: An overview. Mol. Cell. Neurosci. 97, 60-66. doi: 10.1016/j.mcn.2018.12.005

Majbour, N. K., Vaikath, N. N., Van Dijk, K. D., Ardah, M. T., Varghese, S., Vesterager, L. B., et al. (2016). Oligomeric and phosphorylated alpha-synuclein as potential CSF biomarkers for Parkinson's disease. Mol. Neurodegener. 11, 1-15. doi: 10.1186/s13024-016-0072-9

Malek, N., Lawton, M. A., Grosset, K. A., Bajaj, N., Barker, R. A., Ben-Shlomo, Y., et al. (2017). Utility of the new Movement Disorder Society clinical diagnostic criteria for Parkinson's disease applied retrospectively in a large cohort study of recent onset cases. Park. Relat. Disord 40, 40-46. doi: 10.1016/j.parkreldis.2017. 04.006

Manza, P., Zhang, S., Li, C. S., and Leung, H. C. (2016). Resting-state functional connectivity of the striatum in early-stage Parkinson's disease: Cognitive decline and motor symptomatology. Hum. Brain Mapp. 37, 648-662. doi: 10.1002/hbm. 23056

Marek, K., Jennings, D., Lasch, S., Siderowf, A., Tanner, C., Simuni, T., et al. (2011). The Parkinson Progression Marker Initiative (PPMI). Prog. Neurobiol. 95, 629-635. doi: 10.1016/j.pneurobio.2011.09.005

Maruyama, M., Shimada, H., Suhara, T., Shinotoh, H., Ji, B., Maeda, J., et al. (2013). Imaging of tau pathology in a tauopathy mouse model and in Alzheimer patients compared to normal controls. Neuron 79, 1094-1108. doi: 10.1016/j. neuron.2013.07.037

Mashima, K., Ito, D., Kameyama, M., Osada, T., Tabuchi, H., Nihei, Y., et al. (2017). Extremely Low Prevalence of Amyloid Positron Emission Tomography Positivity in Parkinson's Disease without Dementia. Eur. Neurol. 77, 231-237. doi: $10.1159 / 000464322$

Matsuda, H. (2016). MRI morphometry in Alzheimer's disease. Ageing Res. Rev. 30, 17-24. doi: 10.1016/j.arr.2016.01.003

Matsuda, H., Murata, M., Mukai, Y., Sako, K., Ono, H., Toyama, H., et al. (2018). Japanese multicenter database of healthy controls for [(123)I]FP-CIT SPECT. Eur. J. Nucl. Med. Mol. Imaging 45, 1405-1416. doi: 10.1007/s00259018-3976-5

Mattsson, N., Insel, P. S., Donohue, M., Landau, S., Jagust, W. J., Shaw, L. M., et al. (2015). Independent information from cerebrospinal fluid amyloid- $\beta$ and florbetapir imaging in Alzheimer's disease. Brain 138, 772-783. doi: 10.1093/ brain/awu367

Mazzulli, J. R., Xu, Y. H., Sun, Y., Knight, A. L., McLean, P. J., Caldwell, G. A., et al. (2011). Gaucher disease glucocerebrosidase and $\alpha$-synuclein form a bidirectional pathogenic loop in synucleinopathies. Cell 146, 37-52. doi: 10. 1016/j.cell.2011.06.001

McKeith, I. G., Boeve, B. F., Dickson, D. W., Halliday, G., Taylor, J. P., Weintraub, D., et al. (2017). Diagnosis and management of dementia with Lewy bodies: Fourth consensus report of the DLB Consortium. Neurology 89, 88-100. doi: 10.1212/wnl.0000000000004058

McKhann, G. M., Knopman, D. S., Chertkow, H., Hyman, B. T., Jack, C. R. J., Kawas, C. H., et al. (2011). The diagnosis of dementia due to Alzheimer's disease: recommendations from the National Institute on AgingAlzheimer's Association workgroups on diagnostic guidelines for Alzheimer's disease. Alzheimers. Dement. 7, 263-269. doi: 10.1016/j.jalz.2011.03. 005

Melzer, T. R., Watts, R., Macaskill, M. R., Pitcher, T. L., Livingston, L., Keenan, R. J., et al. (2013). White matter microstructure deteriorates across cognitive stages in Parkinson disease. Neurology 80, 1841-1849. doi: 10.1212/WNL. 0b013e3182929f62
Mendoza-Velásquez, J. J., Flores-Vázquez, J. F., Barrón-Velázquez, E., Sosa-Ortiz, A. L., Illigens, B. M. W., and Siepmann, T. (2019). Autonomic dysfunction in $\alpha$-synucleinopathies. Front. Neurol. 10, 1-8. doi: 10.3389/fneur.2019.00363

Meyer, P. T., Frings, L., Rücker, G., and Hellwig, S. (2017). 18F-FDG PET in Parkinsonism: Differential diagnosis and evaluation of cognitive impairment. J. Nucl. Med. 58, 1888-1898. doi: 10.2967/jnumed.116.186403

Mollenhauer, B., Trautmann, E., Taylor, P., Manninger, P., Sixel-Döring, F., Ebentheuer, J., et al. (2013). Total CSF $\alpha$-synuclein is lower in de novo Parkinson patients than in healthy subjects. Neurosci. Lett. 532, 44-48. doi: 10.1016/j.neulet.2012.11.004

Morra, L. F., and Donovick, P. J. (2014). Clinical presentation and differential diagnosis of dementia with Lewy bodies: a review. Int. J. Geriatr. Psychiatry 29, 569-576. doi: 10.1002/gps.4039

Morris, J. C. (1993). The Clinical Dementia Rating (CDR): current version and scoring rules. Neurology 43, 2412-2414. doi: 10.1212/wnl.43.11.2412-a

Morton, R. E., St John, P. D., and Tyas, S. L. (2019). Migraine and the risk of all-cause dementia, Alzheimer's disease, and vascular dementia: A prospective cohort study in community-dwelling older adults. Int. J. Geriatr. Psychiatry 34, 1667-1676. doi: 10.1002/gps.5180

Moscoso, A., Grothe, M. J., Ashton, N. J., Karikari, T. K., Lantero Rodríguez, J., Snellman, A., et al. (2021). Longitudinal Associations of Blood Phosphorylated Tau181 and Neurofilament Light Chain with Neurodegeneration in Alzheimer Disease. JAMA Neurol. 78, 396-406. doi: 10.1001/jamaneurol.2020.4986

Muddapu, V. R., Dharshini, S. A. P., Chakravarthy, V. S., and Gromiha, M. M. (2020). Neurodegenerative Diseases - Is Metabolic Deficiency the Root Cause? Front. Neurosci. 14, 1-19. doi: 10.3389/fnins.2020.00213

Nagano-Saito, A., Washimi, Y., Arahata, Y., Kachi, T., Lerch, J. P., Evans, A. C., et al. (2005). Cerebral atrophy and its relation to cognitive impairment in Parkinson disease. Neurology 64, 224-229. doi: 10.1212/01.WNL.0000149510.41793.50

Nakajima, K., Okuda, K., Matsuo, S., Yoshita, M., Taki, J., Yamada, M., et al. (2012). Standardization of metaiodobenzylguanidine heartto mediastinum ratio using a calibration phantom: Effects of correction on normal databases and a multicentre study. Eur. J. Nucl. Med. Mol. Imaging 39, 113-119. doi: 10.1007/ s00259-011-1963-1

Nakamura, A., Kaneko, N., Villemagne, V. L., Kato, T., Doecke, J., Doré, V., et al. (2018). High performance plasma amyloid- $\beta$ biomarkers for Alzheimer's disease. Nature 554, 249-254. doi: 10.1038/nature25456

Nalls, M. A., Pankratz, N., Lill, C. M., Do, C. B., Hernandez, D. G., Saad, M., et al. (2014). Large-scale meta-analysis of genome-wide association data identifies six new risk loci for Parkinson's disease. Nat. Genet. 46, 989-993. doi: 10.1038/ng. 3043

Nho, K., Risacher, S. L., Crane, P. K., DeCarli, C., Glymour, M. M., Habeck, C., et al. (2012). Voxel and surface-based topography of memory and executive deficits in mild cognitive impairment and Alzheimer's disease. Brain Imaging Behav. 6, 551-567. doi: 10.1007/s11682-012-9203-2

O'Brien, J. L., O’Keefe, K. M., Laviolette, P. S., Deluca, A. N., Blacker, D., Dickerson, B. C., et al. (2010). Longitudinal fMRI in elderly reveals loss of hippocampal activation with clinical decline. Neurology 74, 1969-1976. doi: 10.1212/WNL. 0b013e3181e3966e

O’Brien, J. T., Oertel, W. H., McKeith, I. G., Grosset, D. G., Walker, Z., Tatsch, K., et al. (2014). Is ioflupane I123 injection diagnostically effective in patients with movement disorders and dementia? Pooled analysis of four clinical trials. $B M J$ Open 4:5122. doi: 10.1136/bmjopen-2014-005122

O’Bryant, S. E., Lacritz, L. H., Hall, J., Waring, S. C., Chan, W., Khodr, Z. G., et al. (2010). Validation of the new interpretive guidelines for the clinical dementia rating scale sum of boxes score in the National Alzheimer's Coordinating Center database. Arch. Neurol. 67, 746-749. doi: 10.1001/archneurol. 2010.115

O’Callaghan, C., Hornberger, M., Balsters, J. H., Halliday, G. M., Lewis, S. J. G., and Shine, J. M. (2016). Cerebellar atrophy in Parkinson's disease and its implication for network connectivity. Brain 139, 845-855. doi: 10.1093/brain/awv399

Ochmann, S., Dyrba, M., Grothe, M. J., Kasper, E., Webel, S., Hauenstein, K., et al. (2017). Does Functional Connectivity Provide a Marker for Cognitive Rehabilitation Effects in Alzheimer's Disease? An Interventional Study. J. Alzheimer's Dis. 57, 1303-1313. doi: 10.3233/JAD- 160773

Ogawa, S., Lee, T.-M., Nayak, A. S., and Glynn, P. (1990). Oxygenation-sensitive contrast in magnetic resonance image of rodent brain at high magnetic fields. Magn. Reson. Med. 14, 68-78. doi: 10.1002/mrm.1910140108 
Okuzumi, A., Hatano, T., Fukuhara, T., Ueno, S., Nukina, N., Imai, Y., et al. (2021). $\alpha$-Synuclein Seeding Assay Using RT-QuIC. Methods Mol. Biol. 2322, 3-16. doi: 10.1007/978-1-0716-1495-2_1

Olichney, J. M., Murphy, C., Hofstetter, C. R., Foster, K., Hansen, L. A., Thal, L. J., et al. (2005). Anosmia is very common in the Lewy body variant of Alzheimer's disease. J. Neurol. Neurosurg. Psychiatry 76, 1342-1347. doi: 10.1136/jnnp.2003. 032003

Olsson, B., Lautner, R., Andreasson, U., Öhrfelt, A., Portelius, E., Bjerke, M., et al. (2016). CSF and blood biomarkers for the diagnosis of Alzheimer's disease: a systematic review and meta-analysis. Lancet Neurol. 15, 673-684. doi: 10.1016/ S1474-4422(16)00070-3

Ossenkoppele, R., Jansen, W. J., Rabinovici, G. D., Knol, D. L., van der Flier, W. M., van Berckel, B. N., et al. (2015). Prevalence of amyloid PET positivity in dementia syndromes: a meta-analysis. Jama 313, 1939-1949. doi: 10.1001/ jama.2015.4669

Ossenkoppele, R., Rabinovici, G. D., Smith, R., Cho, H., Scholl, M., Strandberg, O., et al. (2018). Discriminative accuracy of [18F]flortaucipir positron emission tomography for Alzheimer disease vs other neurodegenerative disorders. JAMA - J. Am. Med. Assoc. 320, 1151-1162. doi: 10.1001/jama.2018.12917

Pagonabarraga, J., Soriano-Mas, C., Llebaria, G., López-Solà, M., Pujol, J., and Kulisevsky, J. (2014). Neural correlates of minor hallucinations in nondemented patients with Parkinson's disease. Park. Relat. Disord. 20, 290-296. doi: 10.1016/j.parkreldis.2013.11.017

Palmqvist, S., Schöll, M., Strandberg, O., Mattsson, N., Stomrud, E., Zetterberg, H., et al. (2017). Earliest accumulation of $\beta$-amyloid occurs within the default-mode network and concurrently affects brain connectivity. Nat. Commun. 8:1150. doi: 10.1038/s41467-017-01150-x

Petersen, R. C., Aisen, P. S., Beckett, L. A., Donohue, M. C., Gamst, A. C., Harvey, D. J., et al. (2010). Alzheimer's Disease Neuroimaging Initiative (ADNI): Clinical characterization. Neurology 74, 201-209. doi: 10.1212/WNL. 0b013e3181cb3e25

Petersen, R. C., Doody, R., Kurz, A., Mohs, R. C., Morris, J. C., Rabins, P. V., et al. (2001). Current concepts in mild cognitive impairment. Arch. Neurol. 58, 1985-1992. doi: 10.1001/archneur.58.12.1985

Petersen, R. C., Smith, G. E., Waring, S. C., Ivnik, R. J., Tangalos, E. G., and Kokmen, E. (1999). Mild cognitive impairment: clinical characterization and outcome. Arch. Neurol. 56, 303-308. doi: 10.1001/archneur. 56.3.303

Pirker, W. (2003). Correlation of dopamine transporter imaging with parkinsonian motor handicap: How close is it? Mov. Disord. 18:10579. doi: 10.1002/mds. 10579

Pontifex, M., Vauzour, D., and Minihane, A. M. (2018). The effect of APOE genotype on Alzheimer's disease risk is influenced by sex and docosahexaenoic acid status. Neurobiol. Aging 69, 209-220. doi: 10.1016/j.neurobiolaging.2018. 05.017

Portet, F., Scarmeas, N., Cosentino, S., Helzner, E. P., and Stern, Y. (2009). Extrapyramidal signs before and after diagnosis of incident Alzheimer disease in a prospective population study. Arch. Neurol. 66, 1120-1126. doi: 10.1001/ archneurol.2009.196

Poston, K. L., Ua Cruadhlaoich, M. A. I., Santoso, L. F., Bernstein, J. D., Liu, T., Wang, Y., et al. (2020). Substantia Nigra Volume Dissociates Bradykinesia and Rigidity from Tremor in Parkinson's Disease: A 7 Tesla Imaging Study. J. Parkinsons. Dis. 10, 591-604. doi: 10.3233/JPD- 191890

Postuma, R. B., Berg, D., Stern, M., Poewe, W., Olanow, C. W., Oertel, W., et al. (2015). MDS clinical diagnostic criteria for Parkinson's disease. Mov. Disord. 30, 1591-1601. doi: 10.1002/mds.26424

Postuma, R. B., Poewe, W., Litvan, I., Lewis, S., Lang, A. E., Halliday, G., et al. (2018). Validation of the MDS clinical diagnostic criteria for Parkinson's disease. Mov. Disord. 33, 1601-1608. doi: 10.1002/mds.27362

Prakash, B. D., Sitoh, Y. Y., Tan, L. C. S., and Au, W. L. (2012). Asymmetrical diffusion tensor imaging indices of the rostral substantia nigra in Parkinson's disease. Park. Relat. Disord. 18, 1029-1033. doi: 10.1016/j.parkreldis.2012. 05.021

Prins, N. D., and Scheltens, P. (2015). White matter hyperintensities, cognitive impairment and dementia: An update. Nat. Rev. Neurol. 11, 157-165. doi: 10.1038/nrneurol.2015.10

Probst, C. C., Winter, L. M., Moller, B., Weber, H., Weintraub, D., Witt, K., et al. (2014). Validation of the questionnaire for impulsive-compulsive disorders in
Parkinson's disease (QUIP) and the QUIP-rating scale in a German speaking sample. J. Neurol. 261, 936-942. doi: 10.1007/s00415-014-7299-6

Pyatigorskaya, N., Sanz-Morère, C. B., Gaurav, R., Biondetti, E., Valabregue, R., Santin, M., et al. (2020). Iron imaging as a diagnostic tool for parkinson's disease: A systematic review and meta-analysis. Front. Neurol. 11:366. doi: 10.3389/fneur.2020.00366

Qu, Y., Ma, Y. H., Huang, Y. Y., Ou, Y. N., Shen, X. N., Chen, S. D., et al. (2021). Blood biomarkers for the diagnosis of amnestic mild cognitive impairment and Alzheimer's disease: A systematic review and meta-analysis. Neurosci. Biobehav. Rev. 128, 479-486. doi: 10.1016/j.neubiorev.2021.07.007

Robinson, M., Lee, B. Y., and Hane, F. T. (2017). Recent Progress in Alzheimer's Disease Research, Part 2: Genetics and Epidemiology. J. Alzheimers. Dis. 57, 317-330. doi: 10.3233/JAD- 161149

Rolinski, M., Griffanti, L., Piccini, P., Roussakis, A. A., Szewczyk-Krolikowski, K., Menke, R. A., et al. (2016). Basal ganglia dysfunction in idiopathic REM sleep behaviour disorder parallels that in early Parkinson's disease. Brain 139, 2224-2234. doi: 10.1093/brain/aww124

Rolinski, M., Griffanti, L., Szewczyk-Krolikowski, K., Menke, R. A. L., Wilcock, G. K., Filippini, N., et al. (2015). Aberrant functional connectivity within the basal ganglia of patients with Parkinson's disease. NeuroImage Clin. 8, 126-132. doi: 10.1016/j.nicl.2015. 04.003

Rosenberg-Katz, K., Herman, T., Jacob, Y., Giladi, N., Hendler, T., and Hausdorff, J. M. (2013). Gray matter atrophy distinguishes between Parkinson disease motor subtypes. Neurology 80, 1476-1484. doi: 10.1212/WNL. 0b013e31828cfaa4

Rosenthal, E., Brennan, L., Xie, S., Hurtig, H., Milber, J., Weintraub, D., et al. (2010). Association between cognition and function in patients with Parkinson disease with and without dementia. Mov. Disord. 25, 1170-1176. doi: 10.1002/mds. 23073

Sachdev, P. S., Blacker, D., Blazer, D. G., Ganguli, M., Jeste, D. V., Paulsen, J. S., et al. (2014). Classifying neurocognitive disorders: The DSM-5 approach. Nat. Rev. Neurol. 10, 634-642. doi: 10.1038/nrneurol.2014.181

Saito, S., Yamamoto, Y., and Ihara, M. (2015). Mild Cognitive Impairment: At the Crossroad of Neurodegeneration and Vascular Dysfunction. Curr. Alzheimer Res. 12, 507-512. doi: 10.2174/1567205012666150530202508

Sakakibara, S., Hashimoto, R., Katayama, T., Kenjyo, M., Yokokawa, Y., Saito, Y., et al. (2020). Longitudinal Change of DAT SPECT in Parkinson's Disease and Multiple System Atrophy. J. Parkinsons. Dis. 10, 123-130. doi: 10.3233/JPD191710

Sanchez-Castaneda, C., Rene, R., Ramirez-Ruiz, B., Campdelacreu, J., Gascon, J., Falcon, C., et al. (2009). Correlations between gray matter reductions and cognitive deficits in dementia with lewy bodies and Parkinson's disease with dementia. Mov. Disord. 24, 1740-1746. doi: 10.1002/mds.22488

Sasaki, M., Shibata, E., Kudo, K., and Tohyama, K. (2008). Neuromelanin-sensitive MRI: Basics, technique, and clinical applications. Clin. Neuroradiol. 18, 147153. doi: $10.1007 / \mathrm{s} 00062-008-8018-4$

Sasaki, S. (2018). High prevalence of parkinsonism in patients with MCI or mild Alzheimer's disease. Alzheimers. Dement. 14, 1615-1622. doi: 10.1016/j.jalz. 2018.06.3054

Sawada, H., Oeda, T., Yamamoto, K., Kitagawa, N., Mizuta, E., Hosokawa, R., et al. (2009). Diagnostic accuracy of cardiac metaiodobenzylguanidine scintigraphy in Parkinson disease. Eur. J. Neurol. 16, 174-182. doi: 10.1111/j.1468-1331. 2008.02372.x

Sawada, H., Udaka, F., Kameyama, M., Seriu, N., Nishinaka, K., Shindou, K., et al. (1992). SPECT findings in Parkinson's disease associated with dementia. J. Neurol. Neurosurg. Psychiatry 55, 960-963. doi: 10.1136/jnnp.55.10.960

Scheltens, P., Fox, N., Barkhof, F., and De Carli, C. (2002). Structural magnetic resonance imaging in the practical assessment of dementia: Beyond exclusion. Lancet Neurol. 1, 13-21. doi: 10.1016/S1474-4422(02)00002-9

Schouten, T. M., Koini, M., De Vos, F., Seiler, S., Van Der Grond, J., Lechner, A., et al. (2016). Combining anatomical, diffusion, and resting state functional magnetic resonance imaging for individual classification of mild and moderate Alzheimer's disease. NeuroImage Clin. 11, 46-51. doi: 10.1016/j.nicl.2016. 01.002

Schuff, N., Wu, I. W., Buckley, S., Foster, E. D., Coffey, C. S., Gitelman, D. R., et al. (2015). Diffusion imaging of nigral alterations in early Parkinson's disease with dopaminergic deficits. Mov. Disord. 30, 1885-1892. doi: 10.1002/mds.26325 
Serrano-Pozo, A., Frosch, M. P., Masliah, E., and Hyman, B. T. (2011). Neuropathological alterations in Alzheimer disease. Cold Spring Harb. Perspect. Med. 1, 1-24. doi: 10.1101/cshperspect.a006189

Shaw, L. M., Vanderstichele, H., Knapik-Czajka, M., Clark, C. M., Aisen, P. S., Petersen, R. C., et al. (2009). Cerebrospinal fluid biomarker signature in alzheimer's disease neuroimaging initiative subjects. Ann. Neurol. 65, 403-413. doi: $10.1002 /$ ana. 21610

Sheline, Y. I., Morris, J. C., Snyder, A. Z., Price, J. L., Yan, Z., D’Angelo, G., et al. (2010a). APOE4 allele disrupts resting state fMRI connectivity in the absence of amyloid plaques or decreased CSF A $\beta 42$. J. Neurosci. 30, 17035-17040. doi: 10.1523/JNEUROSCI.3987-10.2010

Sheline, Y. I., and Raichle, M. E. (2013). Resting state functional connectivity in preclinical Alzheimer's disease. Biol. Psychiatry 74, 340-347. doi: 10.1016/j. biopsych.2012.11.028

Sheline, Y. I., Raichle, M. E., Snyder, A. Z., Morris, J. C., Head, D., Wang, S., et al. (2010b). Amyloid Plaques Disrupt Resting State Default Mode Network Connectivity in Cognitively Normal Elderly. Biol. Psychiatry 67, 584-587. doi: 10.1016/j.biopsych.2009.08.024

Shi, Y., and Holtzman, D. M. (2018). Interplay between innate immunity and Alzheimer disease: APOE and TREM2 in the spotlight. Nat. Rev. Immunol. 18, 759-772. doi: 10.1038/s41577-018-0051-1

Shimada, H., Ataka, S., Takeuchi, J., Mori, H., Wada, Y., Watanabe, Y., et al. (2011). Pittsburgh compound B-negative dementia: a possibility of misdiagnosis of patients with non-alzheimer disease-type dementia as having AD. J. Geriatr. Psychiatry Neurol. 24, 123-126. doi: 10.1177/0891988711409410

Shimada, H., Kitamura, S., Shinotoh, H., Endo, H., Niwa, F., Hirano, S., et al. (2017). Association between $A \beta$ and tau accumulations and their influence on clinical features in aging and Alzheimer's disease spectrum brains: A [(11)C]PBB3-PET study. Alzheimer's Dement 6, 11-20. doi: 10.1016/j.dadm. 2016.12.009

Shimada, H., Shinotoh, H., Hirano, S., Miyoshi, M., Sato, K., Tanaka, N., et al. (2013). $\beta$-Amyloid in Lewy body disease is related to Alzheimer's disease-like atrophy. Mov. Disord. 28, 169-175. doi: 10.1002/mds.25286

Sidransky, E., Nalls, M. A., Aasly, J. O., Aharon-Peretz, J., Annesi, G., Barbosa, E. R., et al. (2009). Multicenter analysis of glucocerebrosidase mutations in Parkinson's disease. N. Engl. J. Med. 361, 1651-1661. doi: 10.1056/ NEJMoa0901281

Singleton, A., and Hardy, J. (2019). Progress in the genetic analysis of Parkinson's disease. Hum. Mol. Genet. 28, R215-R218. doi: 10.1093/hmg/ddz183

Spampinato, U., Habert, M. O., Mas, J. L., Bourdel, M. C., Ziegler, M., De Recondo, J., et al. (1991). (99mTc)-HM-PAO SPECT and cognitive impairment in Parkinson's disease: A comparison with dementia of the Alzheimer type. J. Neurol. Neurosurg. Psychiatry 54, 787-792. doi: 10.1136/jnnp.54.9.787

Stenset, V., Bjørnerud, A., Fjell, A. M., Walhovd, K. B., Hofoss, D., Due-Tønnessen, P., et al. (2011). Cingulum fiber diffusivity and CSF T-tau in patients with subjective and mild cognitive impairment. Neurobiol. Aging 32, 581-589. doi: 10.1016/j.neurobiolaging.2009.04.014

Sterling, N. W., Du, G., Lewis, M. M., Dimaio, C., Kong, L., Eslinger, P. J., et al. (2013). Striatal shape in Parkinson's disease. Neurobiol. Aging 34, 2510-2516. doi: 10.1016/j.neurobiolaging.2013.05.017

Sterling, N. W., Lewis, M. M., Du, G., and Huang, X. (2016). Structural imaging and Parkinson's disease: Moving toward quantitative markers of disease progression. J. Parkinsons. Dis. 6, 557-567. doi: 10.3233/JPD160824

Summerfield, C., Junqué, C., Tolosa, E., Salgado-Pineda, P., Gómez-Ansón, B., Martí, M. J., et al. (2005). Structural Brain Changes in Parkinson Disease With Dementia. Arch. Neurol. 62:281. doi: 10.1001/archneur.62.2.281

Tagai, K., Ono, M., Kubota, M., Kitamura, S., Takahata, K., Seki, C., et al. (2021). High-Contrast In Vivo Imaging of Tau Pathologies in Alzheimer's and NonAlzheimer's Disease Tauopathies. Neuron 109, 42.e-58.e. doi: 10.1016/j.neuron. 2020.09.042

Tahmasian, M., Bettray, L. M., van Eimeren, T., Drzezga, A., Timmermann, L., Eickhoff, C. R., et al. (2015). A systematic review on the applications of restingstate fMRI in Parkinson's disease: Does dopamine replacement therapy play a role? Cortex 73, 80-105. doi: 10.1016/j.cortex.2015.08.005

Takamura, T., and Hanakawa, T. (2017). Clinical utility of resting-state functional connectivity magnetic resonance imaging for mood and cognitive disorders. J. Neural Transm. 124, 821-839. doi: 10.1007/s00702-017-1710-2
Tam, C. W. C., Burton, E. J., McKeith, I. G., Burn, D. J., and O’Brien, J. T. (2005). Temporal lobe atrophy on MRI in Parkinson disease with dementia: A comparison with Alzheimer disease and dementia with Lewy bodies. Neurology 64, 861-865. doi: 10.1212/01.WNL.0000153070.82309.D4

Tang, H., Huang, J., Nie, K., Gan, R., Wang, L., Zhao, J., et al. (2016). Cognitive profile of Parkinson's disease patients: a comparative study between early-onset and late-onset Parkinson's disease. Int. J. Neurosci. 126, 227-234. doi: 10.3109/ 00207454.2015 .1010646

Teipel, S., Drzezga, A., Grothe, M. J., Barthel, H., Chételat, G., Schuff, N., et al. (2015). Multimodal imaging in Alzheimer's disease: Validity and usefulness for early detection. Lancet Neurol. 14, 1037-1053. doi: 10.1016/S1474-4422(15) 00093-9

Thobois, S., Prange, S., Scheiber, C., and Broussolle, E. (2019). What a neurologist should know about PET and SPECT functional imaging for parkinsonism: A practical perspective. Park. Relat. Disord. 59, 93-100. doi: 10.1016/j.parkreldis. 2018.08.016

Thomas, G. E. C., Leyland, L. A., Schrag, A. E., Lees, A. J., Acosta-Cabronero, J., and Weil, R. S. (2020). Brain iron deposition is linked with cognitive severity in Parkinson's disease. J. Neurol. Neurosurg. Psychiatry 91, 418-425. doi: 10.1136/ jnnp-2019-322042

Tinaz, S., Courtney, M. G., and Stern, C. E. (2011). Focal cortical and subcortical atrophy in early Parkinson's disease. Mov. Disord. 26, 436-441. doi: 10.1002/ mds. 23453

Tokuda, T., Qureshi, M. M., Ardah, M. T., Varghese, S., Shehab, S. A. S., Kasai, T., et al. (2010). Detection of elevated levels of $\alpha$-synuclein oligomers in CSF from patients with Parkinson disease. Neurology 75, 1766-1772. doi: 10.1212/WNL. 0b013e3181fd613b

Tokuda, T., Salem, S. A., Allsop, D., Mizuno, T., Nakagawa, M., Qureshi, M. M., et al. (2006). Decreased $\alpha$-synuclein in cerebrospinal fluid of aged individuals and subjects with Parkinson's disease. Biochem. Biophys. Res. Commun. 349, 162-166. doi: 10.1016/j.bbrc.2006.08.024

Trivedi, D. (2017). Cochrane Review Summary: Mini-Mental State Examination (MMSE) for the detection of dementia in clinically unevaluated people aged 65 and over in community and primary care populations. Prim. Heal. Care Res. Dev. 2017, 1-2. doi: 10.1017/S1463423617000202

Twohig, D., and Nielsen, H. M. (2019). $\alpha$-synuclein in the pathophysiology of Alzheimer's disease. Mol. Neurodegener. 14:23. doi: 10.1186/s13024-0190320-x

Valotassiou, V., Malamitsi, J., Papatriantafyllou, J., Dardiotis, E., Tsougos, I., Psimadas, D., et al. (2018). SPECT and PET imaging in Alzheimer's disease. Ann. Nucl. Med. 32, 583-593. doi: 10.1007/s12149-018-1292-6

van der Pluijm, M., Cassidy, C., Zandstra, M., Wallert, E., de Bruin, K., Booij, J., et al. (2021). Reliability and Reproducibility of Neuromelanin-Sensitive Imaging of the Substantia Nigra: A Comparison of Three Different Sequences. J. Magn. Reson. Imaging 53, 712-721. doi: 10.1002/jmri.27384

Vandenbossche, J., Deroost, N., Soetens, E., Coomans, D., Spildooren, J., Vercruysse, S., et al. (2012). Freezing of gait in Parkinson's disease: Disturbances in automaticity and control. Front. Hum. Neurosci. 6:1-19. doi: 10.3389/fnhum. 2012.00356

Veitch, D. P., Weiner, M. W., Aisen, P. S., Beckett, L. A., Cairns, N. J., Green, R. C., et al. (2019). Understanding disease progression and improving Alzheimer's disease clinical trials: Recent highlights from the Alzheimer's Disease Neuroimaging Initiative. Alzheimers. Dement. 15, 106-152. doi: 10. 1016/j.jalz.2018.08.005

Verdurand, M., Levigoureux, E., Zeinyeh, W., Berthier, L., Mendjel-Herda, M., Cadarossanesaib, F., et al. (2018). In Silico, in Vitro, and in Vivo Evaluation of New Candidates for $\alpha$-Synuclein PET Imaging. Mol. Pharm. 15, 3153-3166. doi: 10.1021/acs.molpharmaceut.8b00229

Vöglein, J., Paumier, K., Jucker, M., Preische, O., McDade, E., Hassenstab, J., et al. (2019). Clinical, pathophysiological and genetic features of motor symptoms in autosomal dominant Alzheimer's disease. Brain 142, 1429-1440. doi: 10.1093/ brain/awz050

Wakasugi, N., Togo, H., Mukai, Y., Nishikawa, N., Sakamoto, T., Murata, M., et al. (2021). Prefrontal network dysfunctions in rapid eye movement sleep behavior disorder. Park. Relat. Disord. 85, 72-77. doi: 10.1016/j.parkreldis.2021. 03.005

Wang, L., Zang, Y., He, Y., Liang, M., Zhang, X., Tian, L., et al. (2006). Changes in hippocampal connectivity in the early stages of Alzheimer's disease: Evidence 
from resting state fMRI. Neuroimage 31, 496-504. doi: 10.1016/j.neuroimage. 2005.12.033

Wang, Z., Luo, X. G., and Gao, C. (2016). Utility of susceptibility-weighted imaging in Parkinson's disease and atypical Parkinsonian disorders. Transl. Neurodegener. 5, 1-8. doi: 10.1186/s40035-016-0064-2

Wee, C. Y., Yang, S., Yap, P. T., and Shen, D. (2016). Sparse temporally dynamic resting-state functional connectivity networks for early MCI identification. Brain Imaging Behav. 10, 342-356. doi: 10.1007/s11682-015-9408-2

Weiner, M. W., Veitch, D. P., Aisen, P. S., Beckett, L. A., Cairns, N. J., Cedarbaum, J., et al. (2015). 2014 Update of the Alzheimer's Disease Neuroimaging Initiative: A review of papers published since its inception. Alzheimers. Dement. 11, e1-e120. doi: 10.1016/j.jalz.2014.11.001

Weiner, M. W., Veitch, D. P., Aisen, P. S., Beckett, L. A., Cairns, N. J., Green, R. C., et al. (2012). The Alzheimer's Disease Neuroimaging Initiative: a review of papers published since its inception. Alzheimers. Dement. 8, S1-S68. doi: 10.1016/j.jalz.2011.09.172

Weiner, M. W., Veitch, D. P., Aisen, P. S., Beckett, L. A., Cairns, N. J., Green, R. C., et al. (2017). The Alzheimer's Disease Neuroimaging Initiative 3: Continued innovation for clinical trial improvement. Alzheimers. Dement. 13, 561-571. doi: 10.1016/j.jalz.2016.10.006

Weintraub, D., Simuni, T., Caspell-Garcia, C., Coffey, C., Lasch, S., Siderowf, A., et al. (2015). Cognitive performance and neuropsychiatric symptoms in early, untreated Parkinson's disease. Mov. Disord. 30, 919-927. doi: 10.1002/mds. 26170

Wennström, M., Surova, Y., Hall, S., Nilsson, C., Minthon, L., Boström, F., et al. (2013). Low CSF Levels of Both $\alpha$-Synuclein and the $\alpha$-Synuclein Cleaving Enzyme Neurosin in Patients with Synucleinopathy. PLoS One 8:53250. doi: 10.1371/journal.pone.0053250

Williams-Gray, C. H., Foltynie, T., Brayne, C. E. G., Robbins, T. W., and Barker, R. A. (2007). Evolution of cognitive dysfunction in an incident Parkinson's disease cohort. Brain 130, 1787-1798. doi: 10.1093/brain/awm111

Wolters, A. F., van de Weijer, S. C. F., Leentjens, A. F. G., Duits, A. A., Jacobs, H. I. L., and Kuijf, M. L. (2019). Resting-state fMRI in Parkinson's disease patients with cognitive impairment: A meta-analysis. Park. Relat. Disord. 62, 16-27. doi: 10.1016/j.parkreldis.2018.12.016

Wu, S. F., Zhu, Z. F., Kong, Y., Zhang, H. P., Zhou, G. Q., Jiang, Q. T., et al. (2014). Assessment of cerebral iron content in patients with Parkinson's disease by the susceptibility-weighted MRI. Eur. Rev. Med. Pharmacol. Sci. 18, 2605-2608.

Wu, T., Long, X., Zang, Y., Wang, L., Hallett, M., Li, K., et al. (2009). Regional homogeneity changes in patients with Parkinson's disease. Hum. Brain Mapp. 30, 1502-1510. doi: 10.1002/hbm.20622

Wu, X., Li, R., Fleisher, A. S., Reiman, E. M., Guan, X., Zhang, Y., et al. (2011). Altered default mode network connectivity in Alzheimer's disease-A resting functional MRI and Bayesian network study. Hum. Brain Mapp. 32, 1868-1881. doi: $10.1002 / \mathrm{hbm} .21153$

Yamada, G., Ueki, Y., Oishi, N., Oguri, T., Fukui, A., Nakayama, M., et al. (2019). Nigrostriatal Dopaminergic Dysfunction and Altered Functional Connectivity in REM Sleep Behavior Disorder With Mild Motor Impairment. Front Neurol 10:802. doi: 10.3389/fneur.2019.00802

Yoshii, F., Ryo, M., Baba, Y., Koide, T., and Hashimoto, J. (2017). Combined use of dopamine transporter imaging (DAT-SPECT) and (123)Imetaiodobenzylguanidine (MIBG) myocardial scintigraphy for diagnosing
Parkinson's disease. J. Neurol. Sci. 375, 80-85. doi: 10.1016/j.jns.2017. 01.042

Yoshizawa, H., Vonsattel, J. P. G., and Honig, L. S. (2013). Early neuropsychological discriminants for Lewy body disease: An autopsy series. J. Neurol. Neurosurg. Psychiatry 84, 1326-1330. doi: 10.1136/jnnp-2012-304381

Zeighami, Y., Fereshtehnejad, S. M., Dadar, M., Collins, D. L., Postuma, R. B., Mišiæ, B., et al. (2019). A clinical-anatomical signature of Parkinson's disease identified with partial least squares and magnetic resonance imaging. Neuroimage 190, 69-78. doi: 10.1016/j.neuroimage.2017.12.050

Zeighami, Y., Ulla, M., Iturria-Medina, Y., Dadar, M., Zhang, Y., Larcher, K. M. H., et al. (2015). Network structure of brain atrophy in de novo parkinson's disease. Elife 4, 1-20. doi: 10.7554/eLife.08440

Zhang, J., Wei, L., Hu, X., Xie, B., Zhang, Y., Wu, G.-R., et al. (2015). Akineticrigid and tremor-dominant Parkinson's disease patients show different patterns of intrinsic brain activity. Parkinsonism Relat. Disord. 21, 23-30. doi: 10.1016/j. parkreldis.2014.10.017

Zhang, T., Zhao, Z., Zhang, C., Zhang, J., Jin, Z., and Li, L. (2019). Classification of early and late mild cognitive impairment using functional brain network of resting-state fMRI. Front. Psychiatry 10, 1-16. doi: 10.3389/fpsyt.2019. 00572

Zhang, W., Sun, S. G., Jiang, Y. H., Qiao, X., Sun, X., and Wu, Y. (2009). Determination of brain iron content in patients with Parkinson's disease using magnetic susceptibility imaging. Neurosci. Bull. 25, 353-360. doi: 10.1007/ s12264-009-0225-8

Zhou, B., Wen, M., Yu, W. F., Zhang, C. L., and Jiao, L. (2015). The diagnostic and differential diagnosis utility of cerebrospinal fluid $\alpha$-synuclein levels in Parkinson's disease: A meta-analysis. Parkinsons. Dis. 2015:567386. doi: 10. $1155 / 2015 / 567386$

Zhou, J., Greicius, M. D., Gennatas, E. D., Growdon, M. E., Jang, J. Y., Rabinovici, G. D., et al. (2010). Divergent network connectivity changes in behavioural variant frontotemporal dementia and Alzheimer's disease. Brain 133, 1352 1367. doi: 10.1093/brain/awq075

Zucca, F. A., Basso, E., Cupaioli, F. A., Ferrari, E., Sulzer, D., Casella, L., et al. (2014). Neuromelanin of the human substantia Nigra: An update. Neurotox. Res. 25, 13-23. doi: 10.1007/s12640-013-9435-y

Conflict of Interest: The authors declare that the research was conducted in the absence of any commercial or financial relationships that could be construed as a potential conflict of interest.

Publisher's Note: All claims expressed in this article are solely those of the authors and do not necessarily represent those of their affiliated organizations, or those of the publisher, the editors and the reviewers. Any product that may be evaluated in this article, or claim that may be made by its manufacturer, is not guaranteed or endorsed by the publisher.

Copyright (c) 2021 Wakasugi and Hanakawa. This is an open-access article distributed under the terms of the Creative Commons Attribution License (CC BY). The use, distribution or reproduction in other forums is permitted, provided the original author(s) and the copyright owner(s) are credited and that the original publication in this journal is cited, in accordance with accepted academic practice. No use, distribution or reproduction is permitted which does not comply with these terms. 